\title{
The Effectiveness of the Educational Programs of the European Union in Developing the Palestinian Higher Education "the Erasmus+ Program as a Model"
}

\author{
Manal Qwaider \\ Education Faculity \\ Islamic University- Gaza \\ mnal-qwaider@outlook.com
}

Received:6/6/2021

Accepted:7/10/2021

\begin{abstract}
:
The study aims at identifying the degree the educational programs of the European Union affect developing the Palestinian higher education. This study focuses on the most successful and widespread program, which is the Erasmus + program as one of the European Union programs in supporting and developing the higher education in Palestine and improving the opportunities of employment for the alumni of Palestinian universities, as well as measuring the effectiveness of the program in encouraging the mutual development in human resources among universities. The analytical descriptive approach, based on data collection, is used in this study to analyze the current reality of the participation of universities in the program depending on the objectives of the current study. The main results of the study were as follows: the Erasmus+ program has a great role in developing the Palestinian higher education, and it has a positive impact on the international recognition of the Palestinian universities, as the program paved the way for the establishment of strong and varied partnerships between the Islamic University and partner countries in the European Union. Furthermore, there was a great turnout of the students towards the program, as a result of the program's role in qualifying the student for work and employment.
\end{abstract}

Keywords: Higher Education, European Union Programs, Erasmus+ Program. 


\title{
مدى فاعلية برامج الاتحاد الأورويي التعليمية في تطوير التعليم الجامعي القلسطيني-سبرنامج إيراسموس + أنموذجاً
}

\author{
منال نعمان قويدر \\ كلية التربية \\ الجامعة الإنلامية -غزة
}

mnal-qwaider@outlook.com

قبول البحث: 10 / 10210

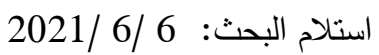

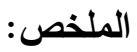

هدفت الدراسة التعرف إلى مدى فاعلية برامج الاتحاد الأوروبي التعليمية في تطوير التعليم الجامعي الفلسطيني، وركزت الدراسة على أكثر

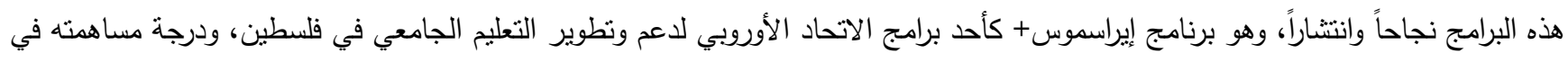

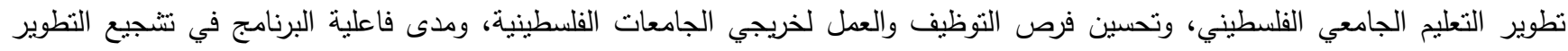

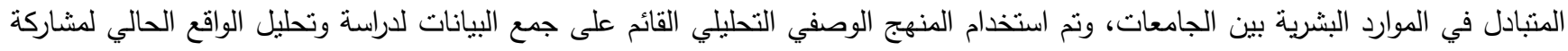

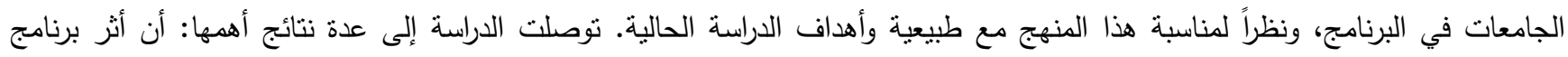

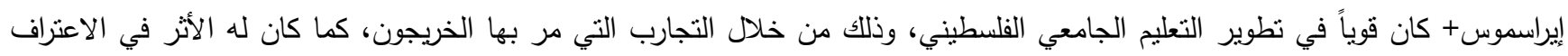

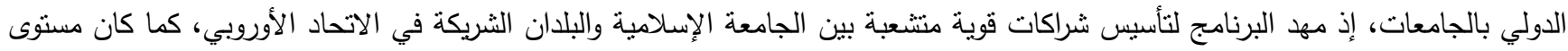

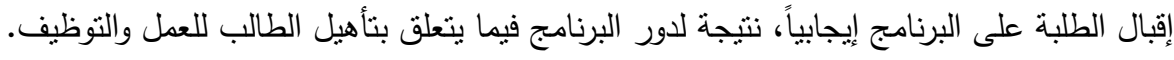

الكلمات المفتاحية: التعليم الجامعي، برامج الاتحاد الأوروبي، برنامج إيراسموس+.

والقاعدة الاقتصادية، والجامعات في فلسطين حديثة التكوين رغم أن التعليم لدى الفلسطينيين قد سبق العديد من دول الجوار، وساهم الفلسطينيون في النهضة التعليمية لمعظم الدول العربية منذ بداية عام النكبة 1948م، والواقع السياسي الذي عاشته فلسطين قد أثر بشكل

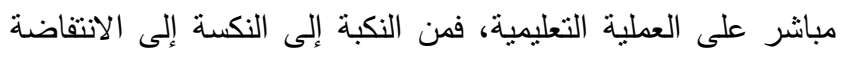

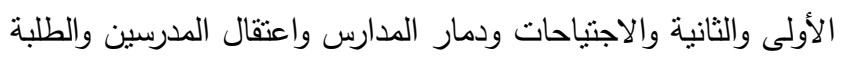
وحرمان الجامعات من الكتب التي يعتبرها الاحتلال ممنوعة وغيرها الكثير من المضايقات، إننا ننظر إلى النعليم العالي كرافعة للفقر وكأساس للكيانية الفلسطينية، وسند لاعم المؤسسة الوطنية التي ستُوِّم الدولة الفلسطينية وأطرها التتموية(19) .

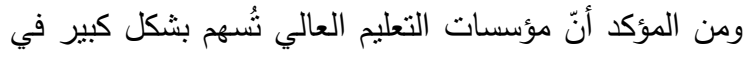
صناعة المعرفة ونقلها للأجيال، كما نسهم في بناء الخبرة الإنسانية

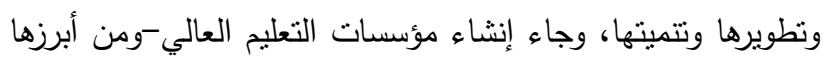

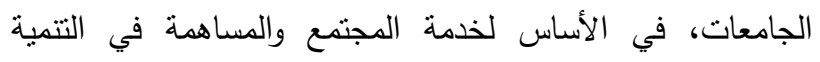
الاجتماعية الثاملة، وتلبية احتياجات المجتمع من الكفاءات والقيادات

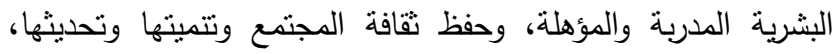

\section{المقدمة}

التعليم هو الاستثمار الحقيقي، ومنطلق التقام وأساس بدايته بل

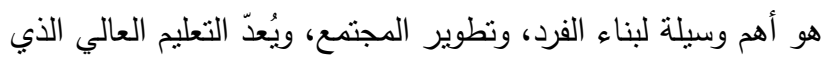

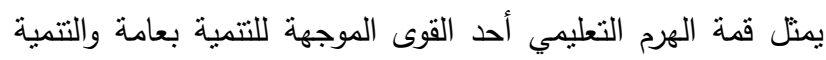
الاقتصادية بخاصة، إذ يحتل موقعاً حيوياً في منظومة التتمية الثاملة الثلة

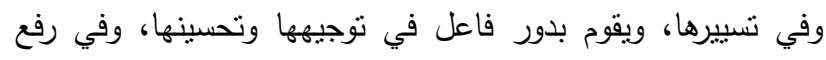
مستوى المجتمع من جميع النواحي الثقافية والفكرية والإدارية والاجتماعية والاقتصادية والسياسيةً والعلمية والعملية.

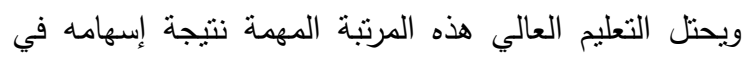
إعداد القوى البشرية المدربة والمؤهلة بالمعارف والمهارات والخبرات

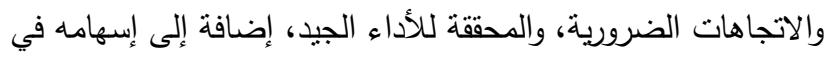

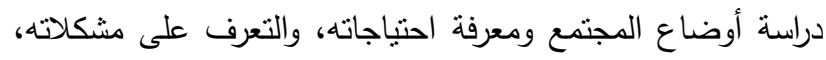

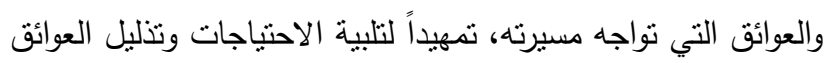
والتغلب على المشكلات وحلها (1 ). ويُعد التعليم من وجهة نظر الفلسطينيين استراتيجية بقاء، خاصة بعد أن فقدا الأرض والوطن، والذي كان يعتبر عماد الثروة 
للطلاب الفلسطينيين عن دعم الاتحاد الأوروبي الثابت لصناع التغيير وقادة الفكر ودعاة السلام، وهي صفات تتوفر لابن لادى الثباب الفلسطيني، كما يعمل الاتحاد الأوروبي والدول الأعضاء معاً من أجل بناء المزيد

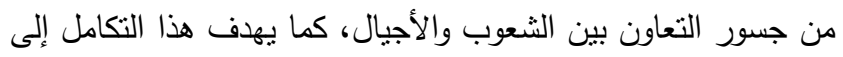

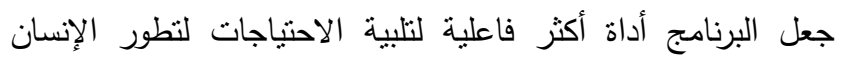

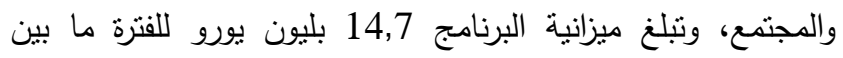
(2014) - 2014)

لذللك سعت الدراسة التعرف إلى أهمية برنامج إيراسموس+

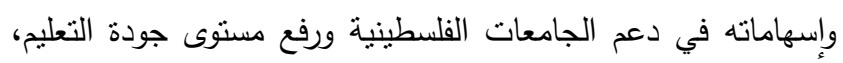
وتعزيز التواصل بين الجامعات وحثها وكافة مؤسسات التعليم العالي في فلسطين على الاستفادة من المنح التي يقدمها البرنامج.

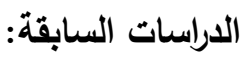

هناك بعض الدراسات السابقة ذات العلاقة بهذا الموضوع؛ الدات

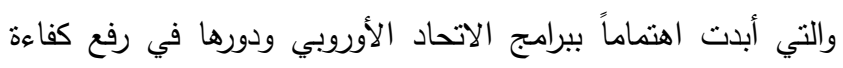

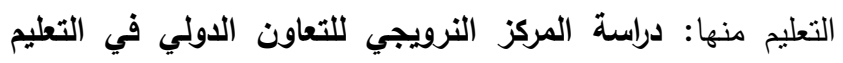
العالي(24) التي هدفت النطرق إلى موضوع برنامج التعاون النرويجي

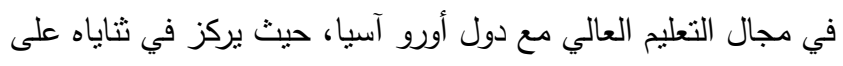

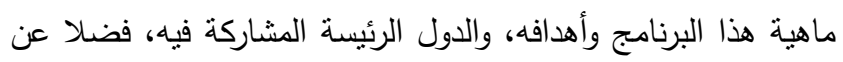
تناول موضوع مشاريع البرنامج التي من المرجح عقدها وتتفيذها خلال فترة زمنية نستمر ثلاث سنوات؛ من أجل تعزيز الأسس التعليمية،

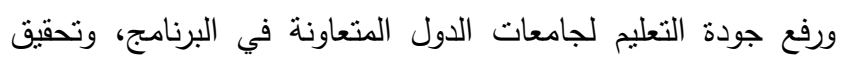

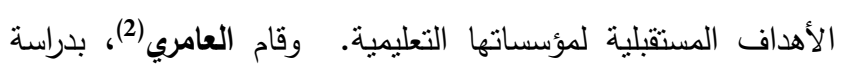

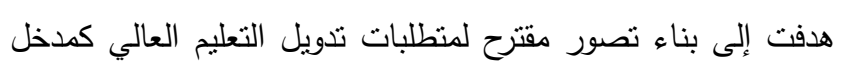

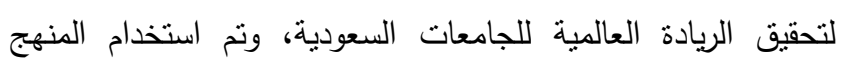

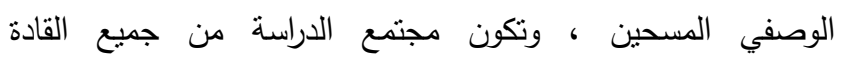

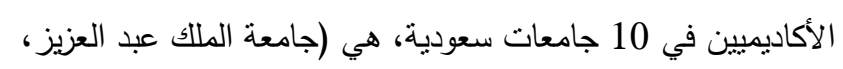

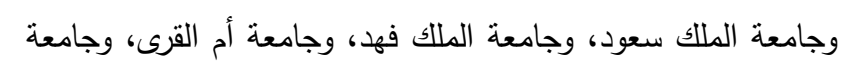

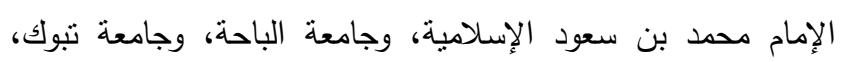

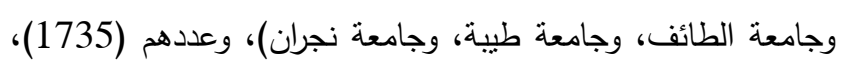

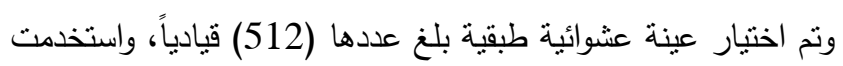

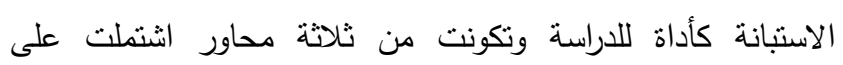
(101)عبارة، وكان من أهم نتائج الدراسة: أنّ نوفر منطلبات تدويل

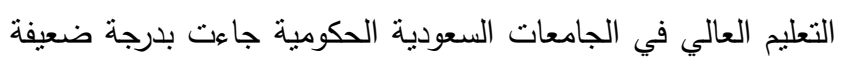

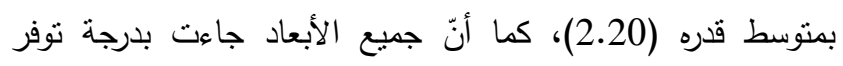

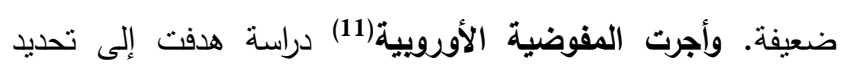

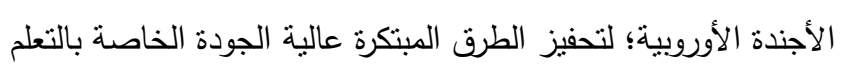

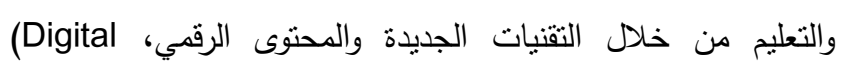
Content)

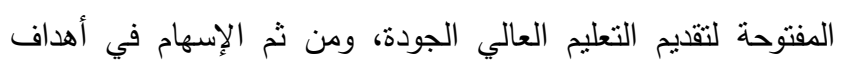

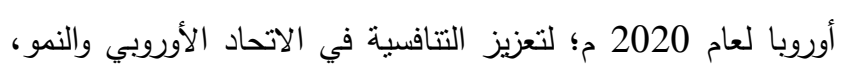

ومسايرة للنطورات الهتجددة، لذلك كان التدريس، والبحث العلمي،

وخدمة الهجمع من أهم أهداف الجامعات (1).

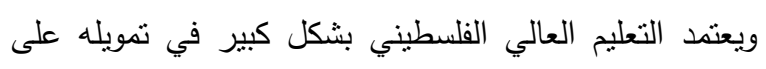
الرسوم الدراسية، فقد أثنارت نشرة أخبار تتموية صادرة عن مجموعة البنك الدولي أن رسوم الطلاب غطت 54\% من من مصاريف الجامعات للعام 1997 / 1998 فيما غطت مساهمات الاتحاد الأوروبي البالغة مليون دولار أمريكي ما نسبته 17 \% \%، من إجمالي التكلفة الجارية

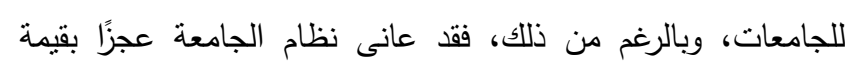

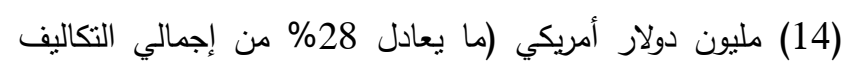

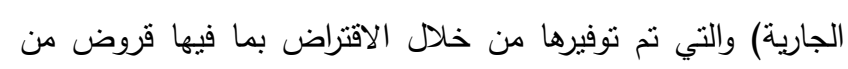
صناديق الثقاعد التابعة لموظفي الجامعات، ولقد أدت الأزمة المالية

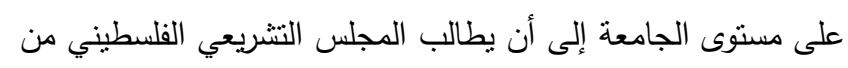

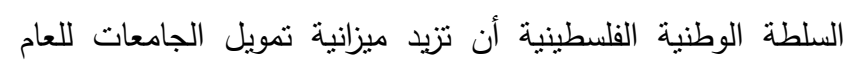
المالي 1998م) وتُعد الثراكة النتربوية من أبرز ما ظهر كمستجدات نربوية

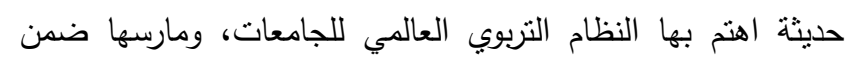

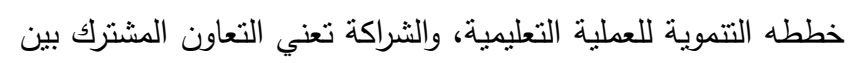

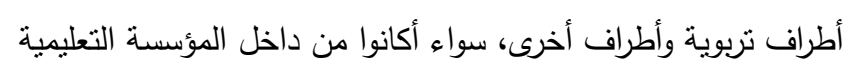

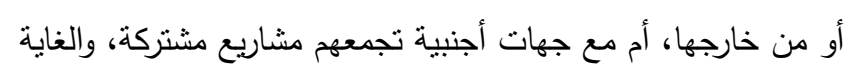

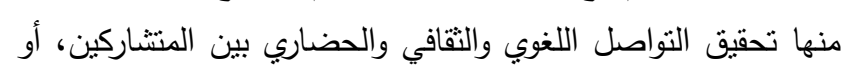

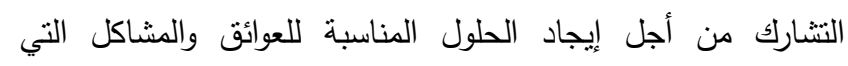

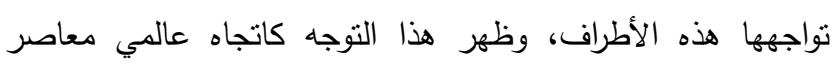
فرضته منطلبات المرحلة، وتتضمن الثراكة كل ما من شأنه التغيير

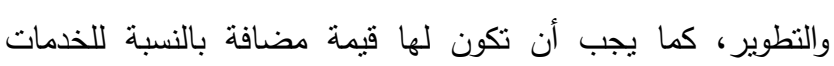
المتعلقة بكل شريك(5).

لذلك تسعى شؤون العلاقات الخارجية في الجامعة الإسلامية

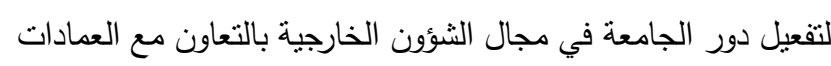

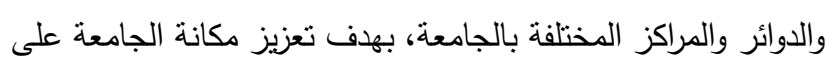

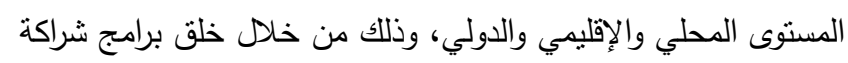

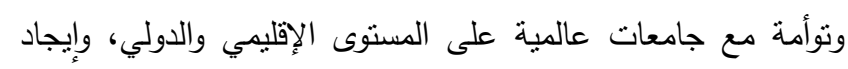

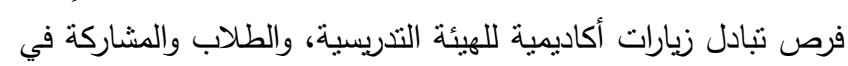
الفعاليات والمؤتمرات الدولية(10). ويعد برنامج Erasmus+ إراسموس + أحد برامج الاتحاد

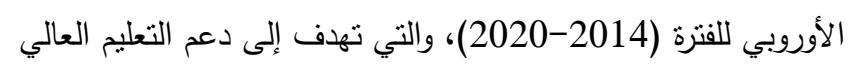

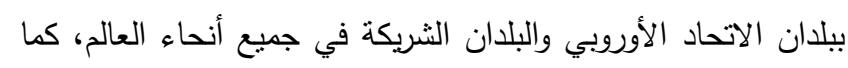

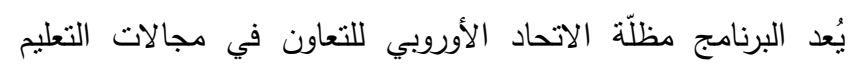

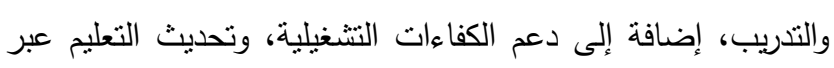

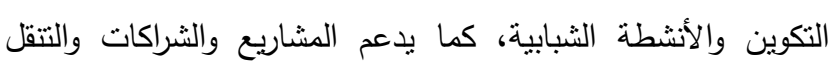
والحوار.

ويقدم البرنامج مِنَاًا دراسية وزمالة، وفُرَص عمل، وبرامج تبادل طلاب، كما تُعبر البرامج والفرص التي يقدمها الاتحاد الأوروبي وزئي 
وبيّن التقرير أنّ الاتحاد الأوروبي اكتسب على مدى السنوات الماضية

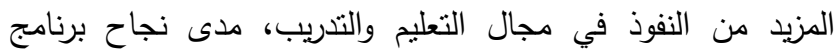
إيراسموس (Erasmus) في مجال التعليم في المجتمعات الأوروبية. كما اختتم التقرير بتوضيح أهم المؤسسات والهيئات في الاتحاد الأوروبي وبيان مهامّها، وتمثلت هذه المؤسسات والهيئات في: المفوضية الأوروبية، البرلمان الأوروبي، منظمة التعاون الاقتصادي

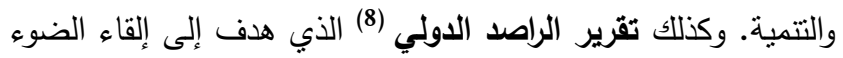

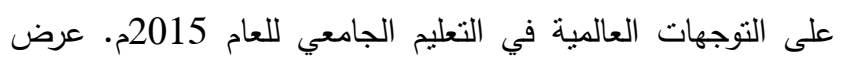
التقرير التطورات العديدة في العملية التقليدية لتنقل الطلبة بين الجامعات، من خلال بيانات تم توفيرها من الإحصاءات والثقارير المتوفرة من عدة مصادر وبيانات خاصة من جامعة أوكسفورد بهذا الخصوص، وأكد الثقرير أنّ التغيرات الثقنية والسياسية والسكانية واسعة النطاق، هي الني تجعل عملية تدويل الجامعات من الأهداف الاستراتيجية للحكومات، لاتهيل (Internationalization) وبيَّن التقرير العوامل التي تؤثر في عملية تنقل الطلبة للاراسة في

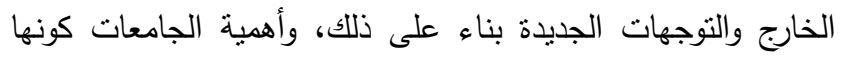
علامات تجارية دولية وذلك عن طريق قيام العديد من الجامعات المرموقة بفتح فروع لها في مختلف دول العالم، وفي مناطق غير تقليدية. وأثنار الثقرير إلى حالات دراسة في العديد من الجامعات

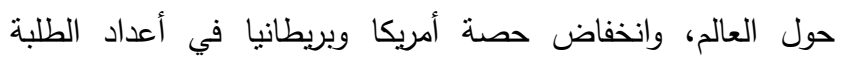
الدوليين، وزيادة حصة أستراليا وكندا. واختتم التقرير بعرض أمتلة من النيان عدة جامعات بريطانية تعمل على إرسال طلبة الدراسات العليا فيها إلى الخارج، منل كلية إمبريال في لندن، التي أنثأت الفصول الدراسية الصيفية لتنمية المهارات المهنية التعاونية، بالتنتارك مع العديد من لناني الجامعات في سنغافورة وهونج كونج.

\section{إثكالية الاراسة وتساؤلاتها:}

تثتير العديد من الدراسات السابقة إلى أنّ التعليم العالي

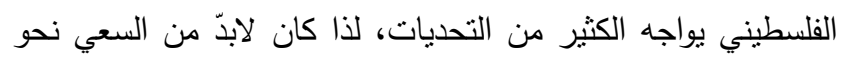
تطوير التعليم العالي الفلسطيني لمواجهة تلك التحديات، ومن هنا جاءت فكرة الاستفادة من خبرة أوروبا الرائدة في هذا المجال، وكيفية

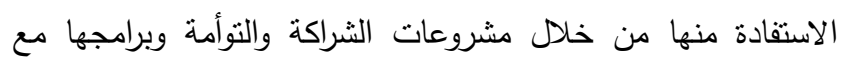
مؤسسات التعليم العالي المختلفة في دول الاتحاد الأوروبي والبلدان الثريكة، وتحاول هذه الدراسة مناقثة إثكالية رئيسية تتمنل في الإني

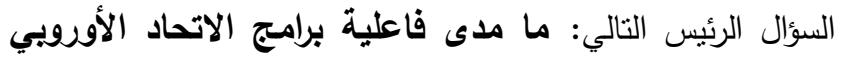
التعليمية في تطوير التعليم الجامعي الفلسطيني في الجامعات القلسطينية بمحافظات غزة؟

\section{ويتفرع عن السؤال الرئيس الأسئلة الفرعية التالية:}

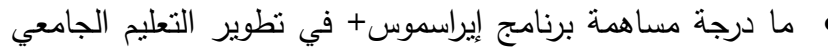
الفلسطيني?
من خلال تحسين القوى العاملة الماهرة، وكذلك المزيد من فرص العمل، كما نسهم الورقة في الأهداف الرئيسة في الاتحاد الأوروبي

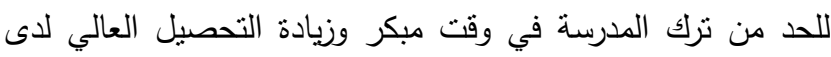
الطلاب. كما تعرض الورقة عدداً من الإجراءات علي مسنوي الاتحاد

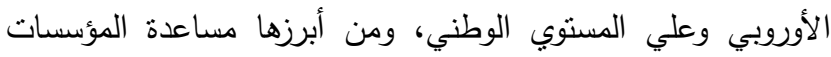
التعليمية والمدرسين والمتعلمين على اكتساب المهارات الرقمية وأساليب التعلم، ودعم التتمية وتوافر الموارد التعليمية المفتوحة، وربط الصفوف

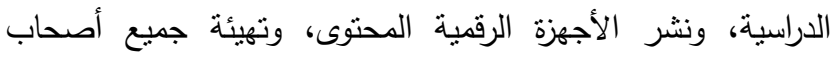
المصلحة (المعلمين والمتعلمين والأسر والثركاء الاقتصاديين والاجتماعيين)؛ لتغيير دور التقنيات الرقمية في المؤسسات التعليمية،

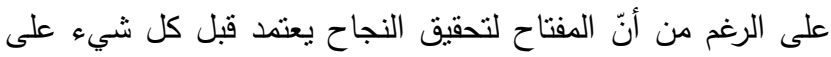

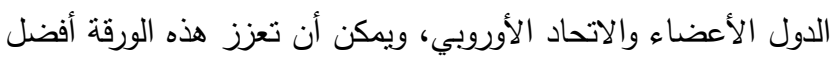

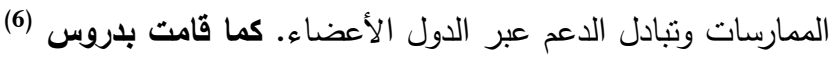
بدراسة هدفت التعرف إلى أهم البرامج التي يقدمها الاتحاد الأوروبي الاعباه

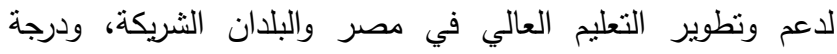

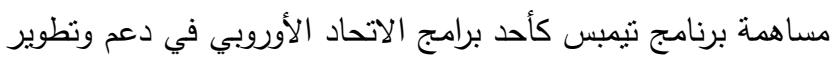

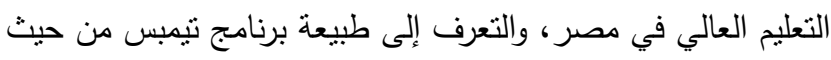

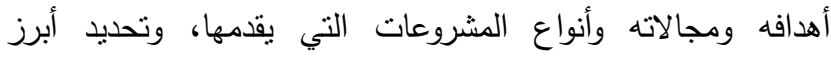

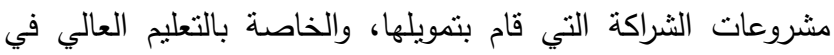
مصر، بالإضافة إلى الكثف عن المشروعات التي استحدثها برنامج تيمبس وانعكاسها على دعم وتطوير التعليم العالي في مصر والبلدان

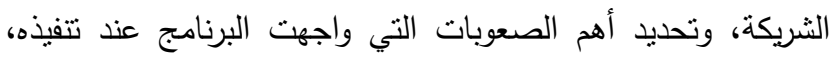
والتي تحدّ من انتتاره، وتقديم بعض الإجراءات المقترحة للتغلب على التى

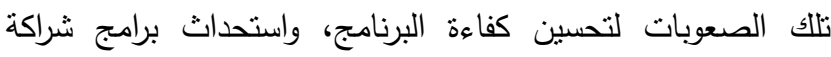

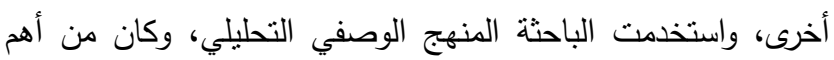

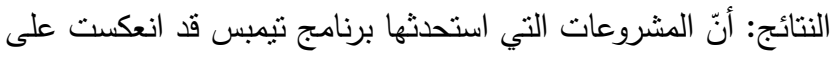

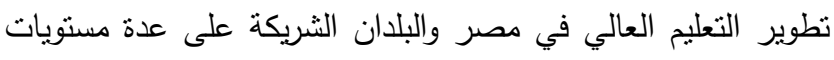
منها مستوى المشاركة إذ اعتبر مستوى مشاركة تيمبس في الدول

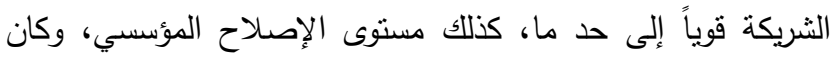

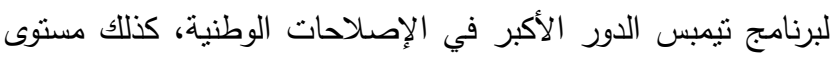

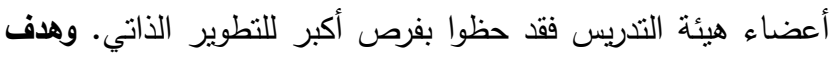

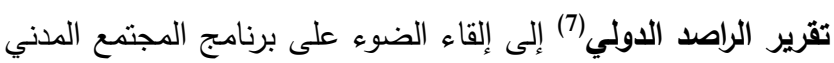

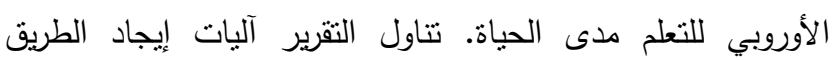

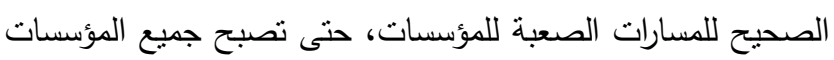

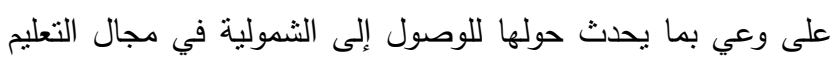

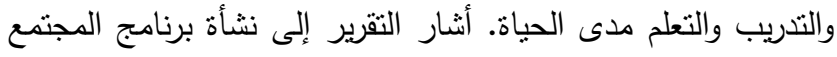

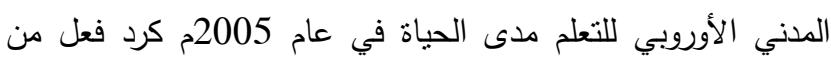

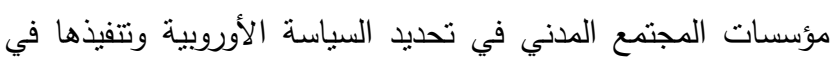

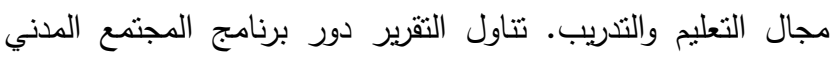

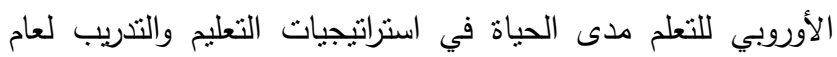
2020م، ما هي الطريقة المفتوحة للتتسيق في مجال التعليم والتدريب. 
الحد الزماني: طبقت هذه الدراسة في الفصل الدراسي الأول للعام 2020/2019

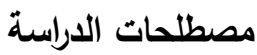

نتتاول الدراسة عدة مفاهيم أساسية، جرى نوضيح أغلبها خلال عرض الدراسة، وأهم هذه الدفاهيم هي:

لالاتحاد الأورويي: "هو شراكة سياسية واقتصادية فريدة من نوعها بين 27 دولة أوروبية ديمقراطية، تهدف إلى السلام والرخاء والحرية

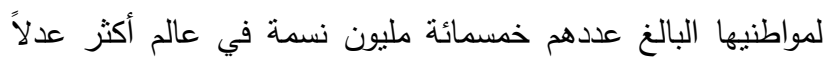

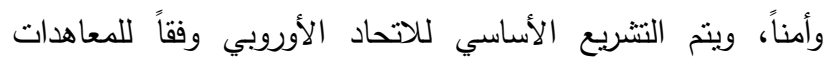

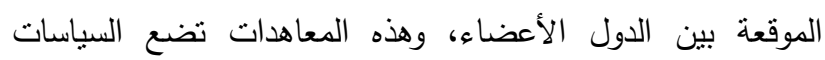
الأساسية للاتحاد الأوروبي، وتوطل الهيكلية المؤسسية والإجراءات التشريعية، ومنها: معاهدة الجماعة الاقتصادية الأوروبية في روما 1957، والقانون الأوروبي الموحد لعام 1986، ومعاهدة ومعاهدة أمستردام 1997، ومعاهدة لنشبونة 2007، وتأسس بناء على الاوربي اتفاقية معروفة باسم معاهدة ماستريخت الموقعة عام 1992، ولكن العديد من أفكاره

$$
\text { موجودة منذ خمسينات القرن الماضي"(15) . }
$$

لبرنامج إراسموس+: "هو برنامج بدعم من المفوضية الأوروبية،

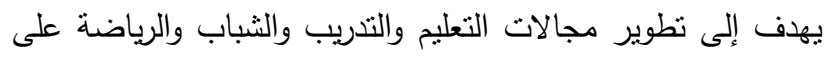

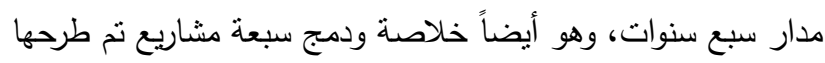

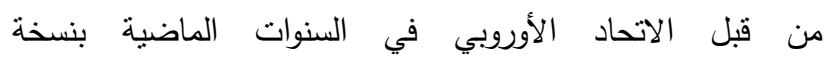

$$
\text { مستحدثة"(22). }
$$

ل الجامعة الإسلامية بغزة: "مؤسسة أكاديمية مستقلة من مؤسسات

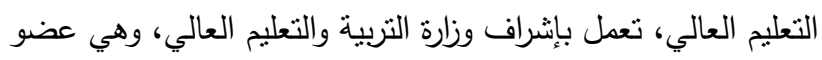
في: اتحاد الجامعات العربية، ورابطة الجامعات الإسلامية، واتحاد الجامعات الإسلامية، ورابطة جامعات البحر الأبيض المتوسط،

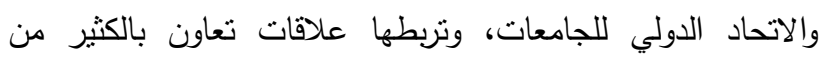

$$
\text { الجامعات العربية والأجنبية"(21). }
$$

لالتعليم الجامعي: "هو التعليم الذي تقدمه الجامعات أو الكليات الجامعية الحكومية والخاصة سواء على مستوى درجة البكالوريوس وما مستواه، أو على مستوى درجني الماجستير والدكتوراه وهو مرحلة التخصص العلمي في أنواعه ومستوياته كافة، رعاية لذوي الكفاية والنبوغ وتتمية لمواهبهم، وسداً لحاجات المجتمع المختلفة في حاضره ومستقبله بما يساير التطور المنير الذي يحقق أهداف الأمة وغاياتها النبيلة في إطار من المحافظة على الأصول الثقافية الدينية للمجتمع ومواكبة كل ما هو جديد وينسجم مع تلك الأصول"(4).
• ما درجة مساهمة برنامج إيراسموس+ في تحسين فرص التوظيف

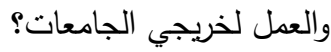
ما مدى فاعلية البرنامج في تشجيع التطوير المتبادل في الموارد

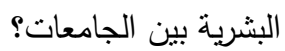

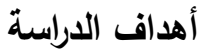

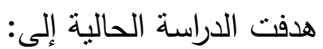

1. التعرف إلى برامج الاتحاد الأوروبي التعليمية، ودورها في تسخير

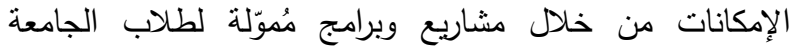
الإسلامية بمحافظة غزة.

2. التعرف إلى أهمية برنامج إيراسموس+ وإسهاماته في دعم الجامعة

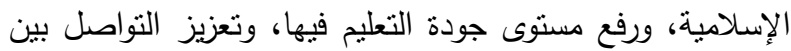
الجامعات، وحثها وكافة مؤسسات التعليم العالي في فلسطين على الاستفادة من المنح التي يقدمها البرنامج.

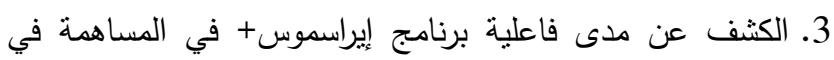
تطوير التعليم العالي في الجامعات الفلسطينية بقطاع غزة.

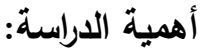

1. نتزامن الدراسة مع الجهود الحالية الني تبذلها الجامعات في تطوير مؤسسات التعليم العالي بمستوياتها الدختلفة.

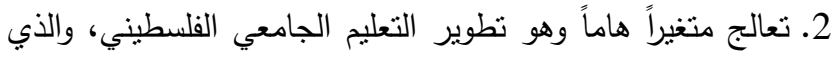

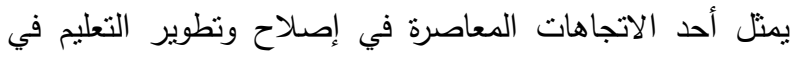
مؤسسات التعليم العالي الفلسطيني. 3. تتوافق مع توجه الجامعات نحو تدعيم أسس الثراكة دولياً بين مختلف الجامعات، لتحقيق مراكز متقدمة في سباق تصنيف

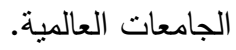

4. حث الجامعات الفلسطينية على الاستفادة من البرامج التي يقدمها الاتحاد الأوروبي، والمساهمة في البرنامج من خلال مشاركتهم في الإني جولات الاختيار ، ودعوة لتقديم مقترحات ومشاريع تشمل مؤسسات

$$
\text { التعليم العالي وتتفيذها. }
$$

5. تعد هذه الدراسة مدخلاً لإجراء دراسات مستقبلية في مجال تطوير التهات التعليم الجامعي ودور برامج الاتحاد الأوربي في جودنه.

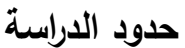

تتحدد الدراسة الحالية بالحدود الثالية: الحد الموضوعي: اقتصرت الدراسة على التعرف إلى مدى فاعلية برامج الاتحاد الأوروبي التعليمية في تطوير التعليم الجامعي

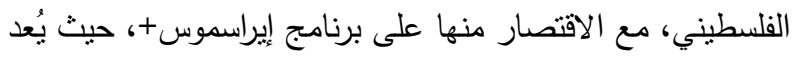
أحد البرامج التي طبقت لتطوير التعليم العالي في الجامعات الفلسطينية. الحد المكاني: الجامعة الإسلامية بغزة. 
وبرنامج إيراسموس مندس Erasmus Mendus، تأسس عام

2009 ويهدف إلى تحسين جودة النعليم العالي عبر تقديم منح، وفتح مجال التعاون الأكاديمي بين أوروبا ودول العالم أجمع، وتعزيز الحودار

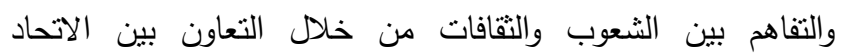
الأوروبي ودول العالم الثالث في المجالات الأكاديمية. ويحتوي على لإنى عدة برامج كل واحد منها يختص بدولة أو مجموعة من الدول ويتم

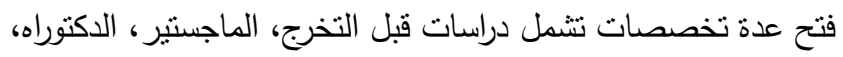

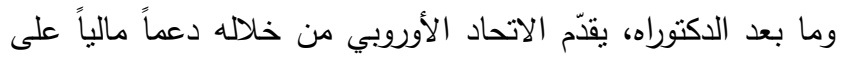

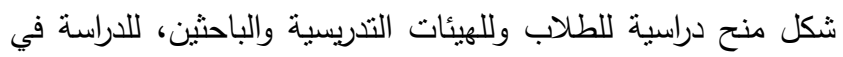

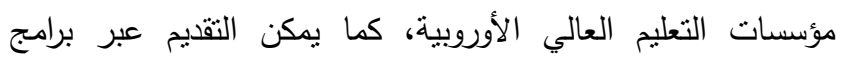

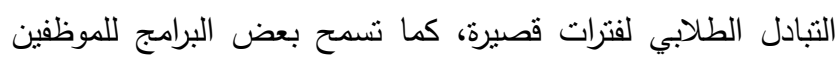
الأكاديميين بالتقديم للاستفادة من الخبرات في الجامعات المختلفة(9).

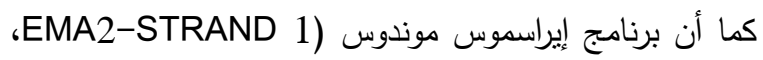
قائم على شراكة تضم 20 جامعة من شمال أفريقيا من إنماند 1

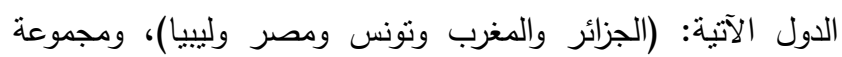

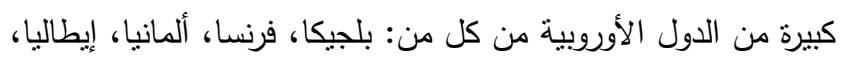

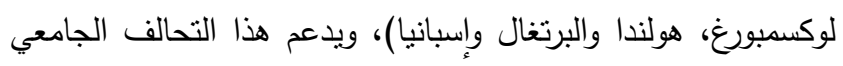

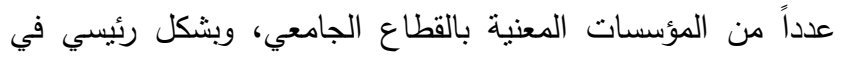

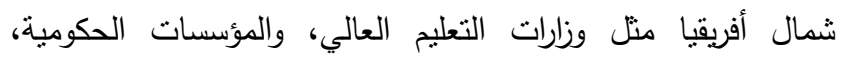

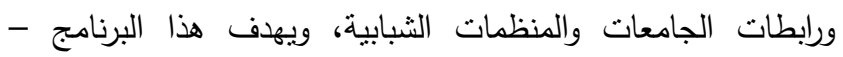
الممول من المفوضية الأوروبية - إلى (9): • • الترويج والتعريف بالتعليم العالي الأوروبي. • تحسين فرص المسار الوظيفي للطلاب. • تعزيز التفاهم بين النقافات من خلال التعاون مع دول شمال

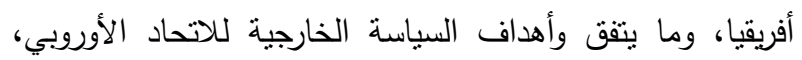
وذلك بغية المساهمة في تحقيق التتمية المستدامة في شمال أفريقيا في مجال التعليم العالي. ولي.

ويمول الاتحاد الأوروبي منحاً للطلاب الذين يُعدون أطروحات

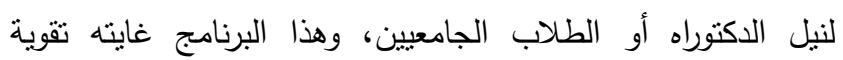

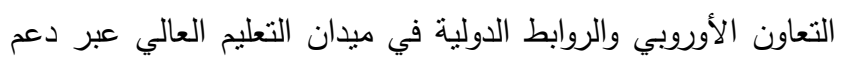
شهادات الماستر والدكتوراه الأوروبية من المستوى الرفيع، والسماح

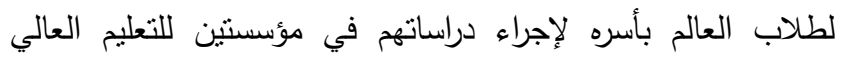

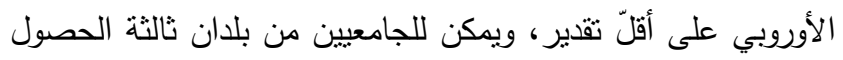

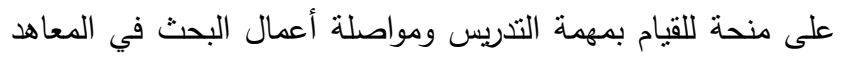

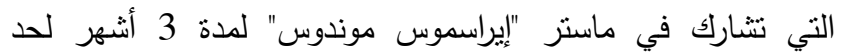
أقصى. ويمكن للجامعيين الأوروبيين الحصول على منحة للمساهمة

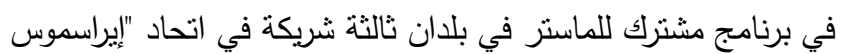
موندوس(14). 6. أما بالنسبة للدول المشاركة في هذا المشروع: يتضمن التثثيل

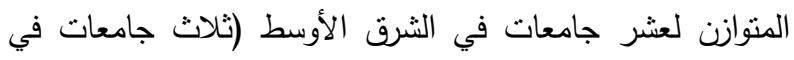

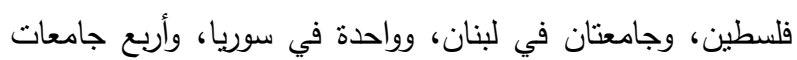

•* منهج الدراسة: للإجابة عن مشكلة الدراسة وتساؤلاتها وتحقيق أهدافها، استخدمت الدراسة المنهج الوصفي التحليلي الذي يعتمد على تجميع الحقائق والمعلومات، ثم مقارنتها وتحليلها وتفسيرها للوصول إلى تعميمات مقبولة، كما تّّ عقد مقابلات مع مختصين

$$
\text { لتحقيق هدف الدراسة. }
$$

ث) تقبيمات الدراسة: تم معالجة فاعلية برامج الاتحاد الأوروبي التعليمية في تطوير التعليم الجامعي الفلسطيني من خلال الارتكاز

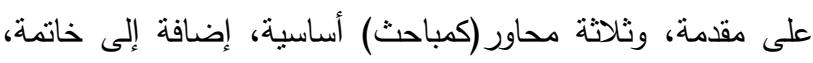
وتوصيات، وهي على النحو التالي:

• المحور الأول: التعريف ببرامج الاتحاد الأوروبي الخاصة بقطاعات النعليم. • المحور الثاني: أهمية برنامج إيراسموس+. • المحور الثالث: دور البرنامج وإسهاماته في دعم الجامعات أكاديمياً (الجامعة الإسلامية كنموذج).

المحور الأول: التعريف ببرامج الاتحاد الأورويي الخاصة بقطاعات التعليم.

\section{(برنامج إراسموس موندوس Erasmus Mendus، تيمبس)}

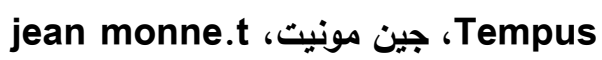

ركز الاتحاد الأوروبي على تعزيز التعاون الفكري من خلال

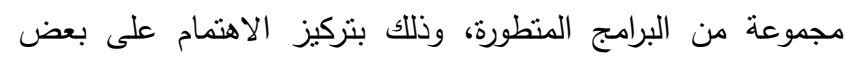

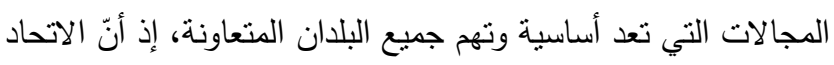

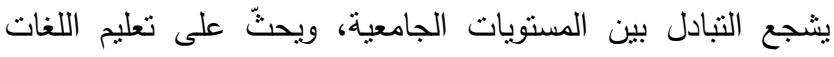

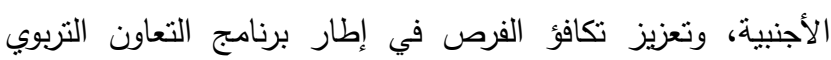
الأوروبي Socrates، كما يسهم في إنشاء صندوق مشترك للأعمال البحثية والإحصاءات (EURYDICE)، ويبلع عدد الدول الأعضاء

$$
\text { في أولاً: برنامسج إيراسموس موندوس: الأوروبي ثمانية وعرين دولة(5). }
$$

برنامج الإيراسموس هو برنامج أوروبي نم تأسيسه عام 1987

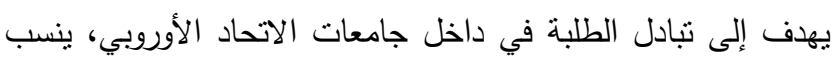
الاسم إيراسموس إلى الفيلسوف الهولندي دسيدريوس إيراسموس لهاس (Desiderius Erasmus Roterodamus) الإنسانية في أوروبا وصاحب مؤلفات عديدة في التربية والتعليم، كما

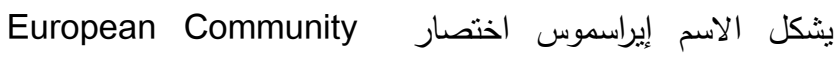
Action Scheme for the) Mobility of University .9) (Students 
• • وتتجدد المنح المقدمة من منظمةErasmus Mundus سنوياً والتي تفيد طلاب الثرق الأوسط خاصةً، وتتعدد منطد كالتالي (20):

Technische الجامعة الني تنرأس المشروع AVEMPACE Universität Berlin, Germany UNIVERSITY الجامعة التي تترأس المشروع PHONIX ALMERIA, Spain:OF Université d'Aix- الجامعة التي تترأس المشروع HERMES Marseille, France

University of الجامعة التي تترأس المشروع PEAC Santiago de Compostela, Spain برنامج منح2 peace : هي واحدة من أهم المنح المقدمة عن طrasmus Mundus

برنامج منح|| PEACE : هو نتاج نعاوني بين المؤسسات

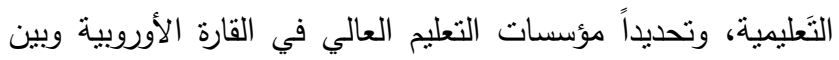
مؤسسات التعليم العالي في منطقة الثرق الأوسط والدول العربية

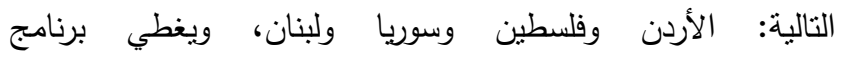
منح PEACE2 عدة مجالات هي كالتالي:

• برنامج البكالوريوس، وبرنامج الماجستير، وبرنامج الدكتوراه،

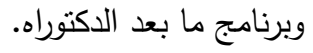

• • الأكاديميون والعاملون ضمن هيئات تدريسية. أما الفئات المستهدفة في هذه المنح فهي كالتالي (20): 1. الفئة المستهدفة الأولى (TG1): تنثمل الطلاب المسجلين وأعضاء هيئة التدريس والعاملين في واحدة من الجامعات

$$
\text { المشاركة في المشروع. }
$$

2. الفئة المستهدفة الثانية(TG2): تشمل المرشحتين من الاتحاد الأوروبي ومن الثرق الأوسط (حملة الجنسيات الأوروبية والأردنية

$$
\text { واللبنانية والفلسطينية والسورية). }
$$

3. الفئة المستهدفة الثالثة:(TG3) هذه الفئة نتشمل المرشحين من دول الشرق الأوسط فقط. تغطي هذه الفئة المواطنين الذين يعانون من

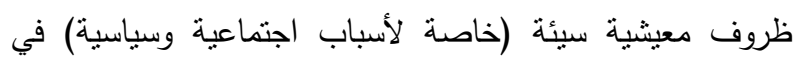

$$
\text { دول الثرق الأوسط الأربع المشاركة في المشروع. }
$$

\section{ثانياً: برنامج TEMPUS}

بدأ البرنامج عام (1990م)، ليدعم تحديث التعليم العالي في

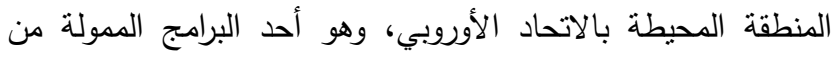
الاتحاد الأوروبي، ويهدف إلى دعم وإصلاح ونطوير أنظمة التعليم

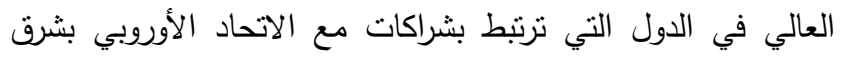

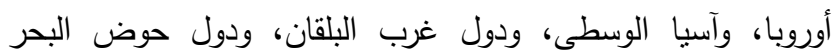

في الأردن) وعشر جامعات في أوروبا (بلجيكا، جمهورية التنيك، فرنسا، ألمانيا، بولندا، البرتغال، السويد ،واسبانيا ، والمملكة

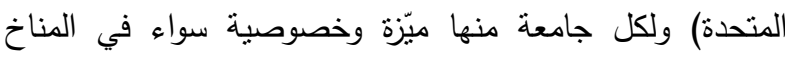

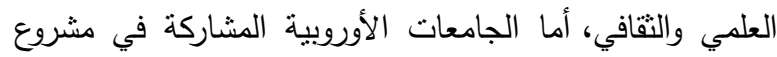
فهي (20):PACE2

University of Santiago de Compostela .1 تتميز بجودة التعليم وشمولها على أغلب التخصصات.

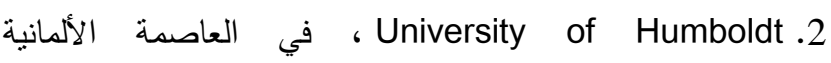
برلين، وتصنف من ضمن أفضل (50) جامعة في العالم، وثالث أفضل جامعة في ألمانبا.

Bielsko-Biala School of Financial and Law .3 هي مدرسة الحقوق والتمويل وبالإضافة إلى الجانب الأكاديمي المتميز تهنم بالجانب العملي والخبرة للطلاب.

4 University of Minho في البرتغال، تحتل مكانة مرموقة في

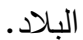

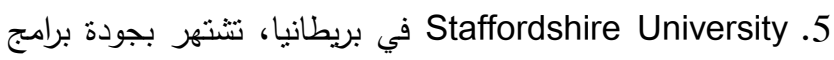

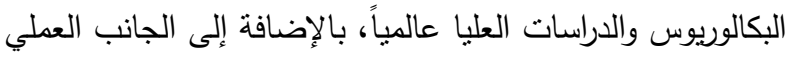

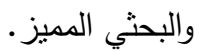

6niversity of Perpignan Via Domitia .6 في فرنسا، تتصف بمكانتها المميزة وتتوع الاختصاصات.

University of Nantes .7 تتميز بتعدد التخصصات بالإضافة إلى منطقتها الجذابة.

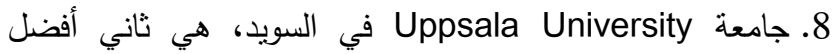

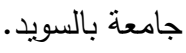
9. جامعة Masaryk University وهي ثاني أكبر جامعة في مدينة التشيك، تتميز بجودة البحوث العلمية عالمياً.

10. وهي من الجامعات التي تحتل مكانة مميزة في بلجيكا.

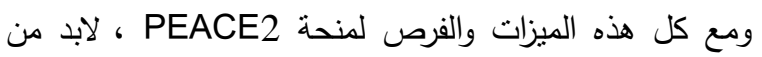

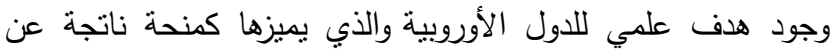
اتحاد لمؤسسات التعليم العالي الأوروبية، وتمثلت الأهداف في التالي:

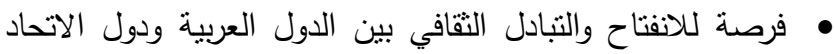
الأوروبي. • • إرسال واستضافة الطلاب والباحثين ذوي الموهبة والثقافة. • التبادل الفعّال للطلاب الذي يساهم في نقل المعرفة والخبرة بما يضمن جودة الثهادات والخبرات العالمية. • مساندة الثعوب التي تعاني من الظروف المعيشية السيئة من دول

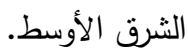




\section{Jالثاً: برنامج جين مونيه Jean Monnet}

تمّ إطلاق برنامج "جين مونيه" في عام 1989 بهدف تشجيع

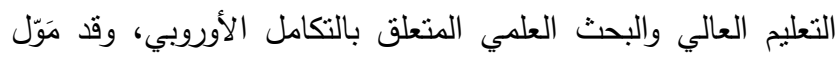

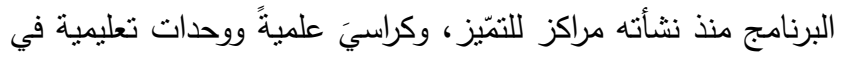
72 بلداً في خمس قارات، والبرنامج تدرج في ثلاث مراتئ مراحل هي:

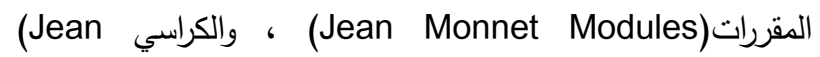
Monnet chairs) هذه المنح حسب خبرة الجامعات وتدرجها في الحصول على هذه ولهات

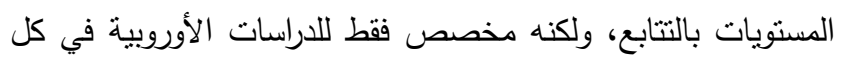
مجالاتها السياسية والثقافية والاجتماعية والاقتصادية. ويُنسب برنامج "جين مونيه" إلى السياسي والدبلوماسي الفرنسي والفي والهي "جين مونيه" الذي يعتبر مهندس الوحدة الأوروبية، وتم تصميم أنشطة ولئي جين مونيه لتعزيز التميز في التنريس والبحث في مجال دراسات

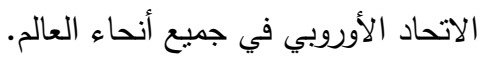

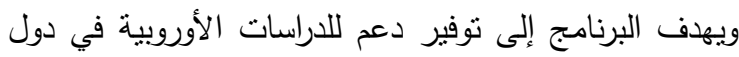

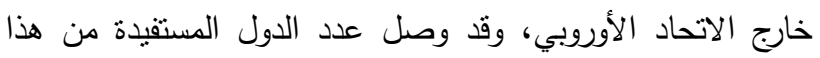

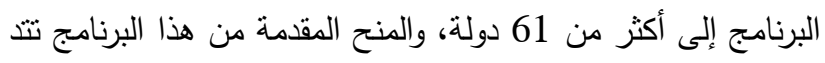

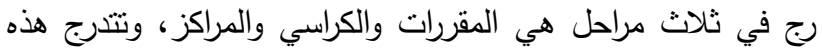

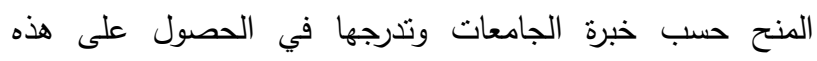
المستويات بالتتابع، ولكن البرنامج مخصص فقط للاراسات الأوروبية

في كل مجالاتها السياسية والنقافية والاجتماعية والاقتصادية (6).

المحور الثاني: أهمية برنامج إيراسموس+

إيراسموس+ هو برنامج جديد يجمع بين برامج الاتحاد الأوروبي

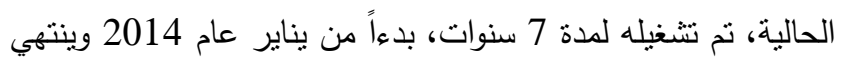

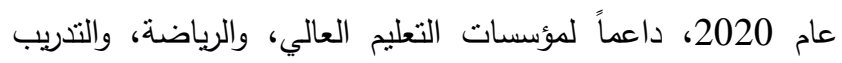

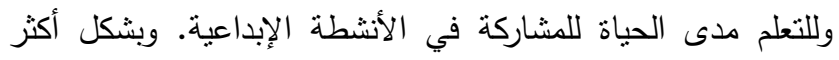
تحديداً إيراسموس + أو إيراسموس بلس، يهدف إلى تطوير التعليم

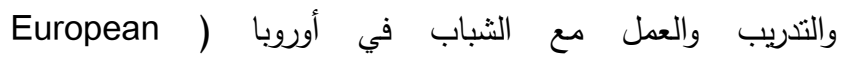

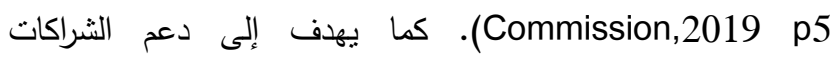
الأكاديمية وغيرها وتعزيز التعاون بين المؤسسات والمنظمات الثبابية،

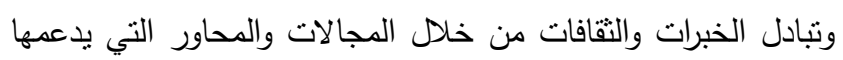

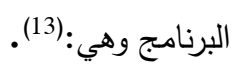

• المحور الأول: محور التبادل الأكاديمي الدولي للأفراد، والذب لبي

يهدف إلى تعزيز تتقل الطلبة والموظفين من وإلى الدول الثريكة.

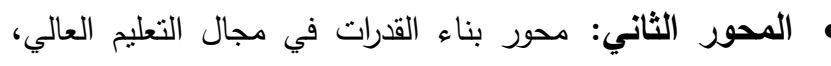
لتعزيز التعاون والثراكات التي يكون لها أثر على تحديث لثئ وتدويل

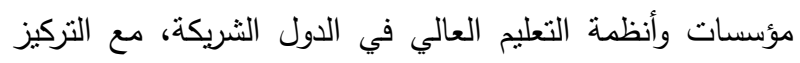
بشكل خاص على الدول الثريكة المجاورة للاتحاد الأوروبي.
الأبيض المتوسط، وينت ذلك بشكل أساسي من خلال تأسيس اتحاد من الجامعات تتعاون من أجل تنفيذ المشروعات الأوروبية المشتركة،

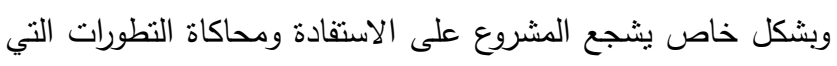
قام بها الاتحاد الأوروبي في مجال التعليم العالي (5). كما بهدف البرنامج إلى التقارب الاختياري لألنابي لأنظمة التعليم

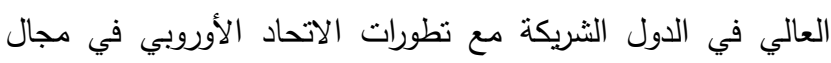
التعليم العالي، بالإضافة إلى تعزيز التعاون بين المؤسسات، وانتهى البرنامجIII TEMPUS عام (2006م)، وانطلق بعد ذللك برنامج

$$
\text { تمبوس IV في عام(2008م) (17). }
$$

إن الهدف العام لبرنامج تيمبس هو التعاون والتتقل في مجال

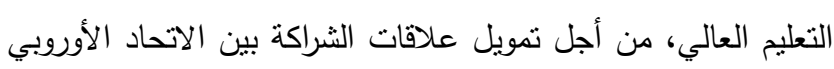

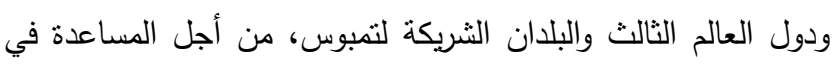

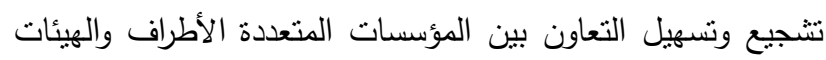

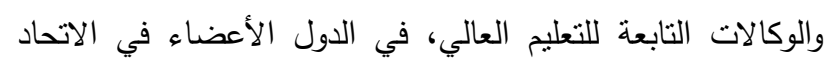

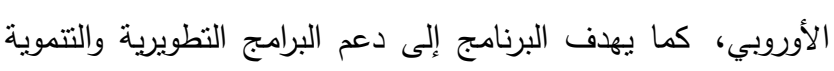

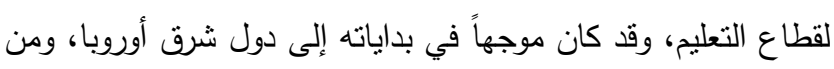

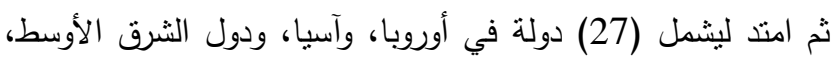
ويمكن تحديد أهداف برنامج تمبوس كالتالي (17):

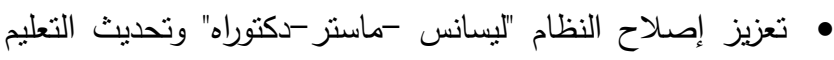
العالي في البلدان الثريكة.

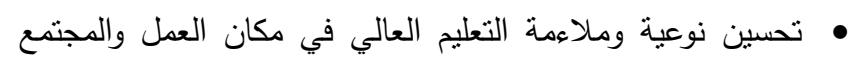
في البلدان الثريكة.

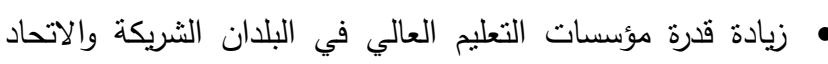

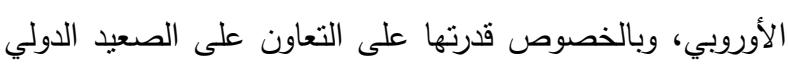

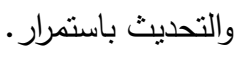
• مساعدة على فتح عالم العمل والمجتمع ككل، وتعزيز التتمية المتبادلة في الموارد البشرية. • تعزيز التفاهم المتبادل بين الثعوب والثقافات في الاتحاد الأوروبي

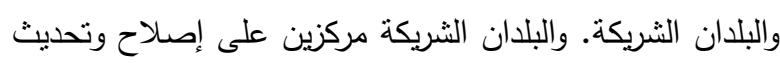

$$
\text { التعليم العالي. }
$$

ويقدم البرنامج المنح للمؤسسات والأفراد، ويُمن لمؤسسات

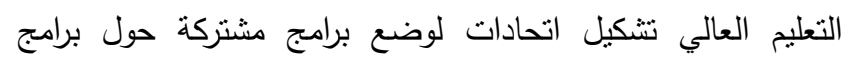

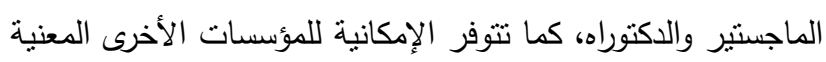

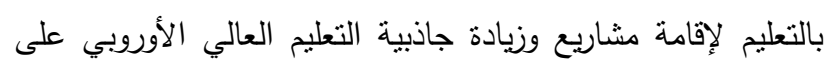

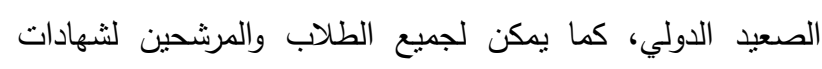

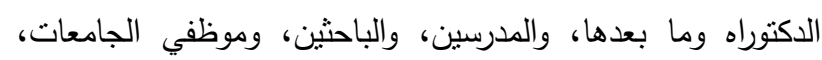

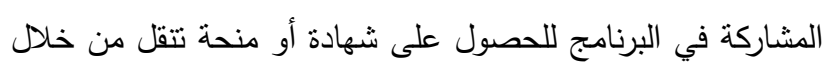

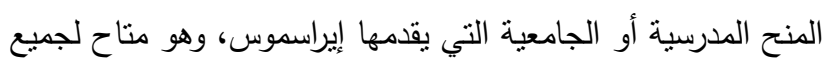
دول العالم (6). 
المشتركة، ومنذ عام (1995م)، أدمجج هذا البرنامج في برامج الاتحاد الأوروبي Socrates والذي يشمل جميع أنواع التعليم ومستوياته،

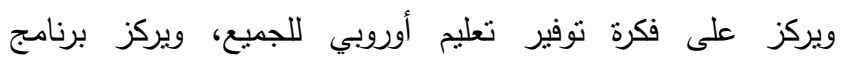
ERASMES+

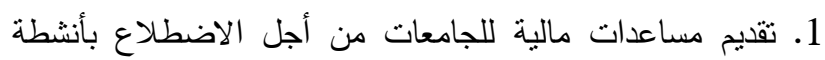

$$
\text { ذات أبعاد أوروبية. }
$$

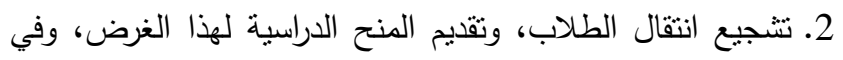
هذا الصدد نم إقرار مجموعة من القواعد التي تيسر الاعتراف الأكاديمي.

وفي عام 2015م أضيف للبرنامج عمل جديد، وهو إعطاء

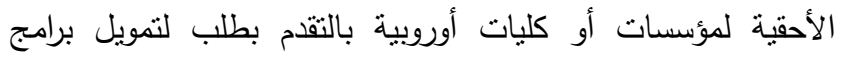

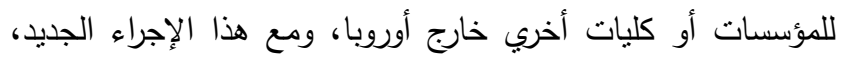
الذي يُعرف باسم الدولية للتتقل(ICM) تمكنت مؤسسات التعليم التحراه العالي من إرسال طلاب من المرحلة الجامعية الأولى أو طلاب من

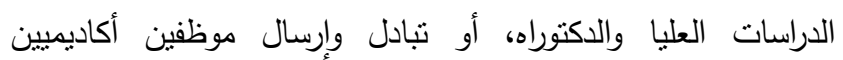
وإداريين إلى البلد الثريك للنتريب أو النعليم.

\section{أما عن الأهداف المحددة للبرنامج فتمثلت في(16):}

• تشيع إصلاح وتحديث النعليم العالي في الدول الثريكة. رفع مستوى جودة التعليم العالي وتوثيق ارتباطه بعالم الأعمال والمجتمع في الدول الثريكة.

• رفع قدرات مؤسسات التعليم العالي في الدول الثريكة والاتحاد

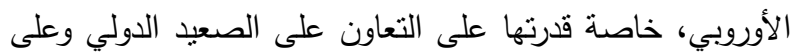

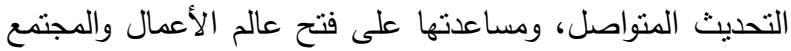

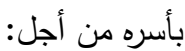
• التغلّب على الاختلاف بين الدول في قطاع التعليم العالي، وكذلك بين المؤسسات في كل بلد على حدة تحسين سياسات تداخل الاختصاصات بين الكليات في الجامعات المختلفة، وفي كل جامعة على حدة. • تحسين فرص التوظيف والعمل لخريجي الجامعات. • إلقاء المزيد من الضوء على التعليم العالي بالبلدان الأوروبية

$$
\text { لجعلها جاذبة على الصعيد العالمي. }
$$

• تشجيع التطور المتبادل في الموارد البشرية.

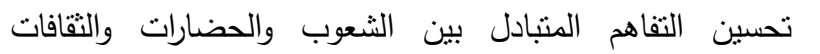
المختلفة في الاتحاد الأوروبي والدول الشريكة.

المحور الثالث: دور البرنامج وإسهاماته في دعم الجامعة الإسلامية أكاديمياً.

ركزت العلاقات الخارجية في الجامعة الإسلامية مجهودها في تدويل التعليم عبر توفير منح دراسية لدرجتي الماجستير والدكتوراه للكوادر الأكاديمية المتميزة في الجامعة، وقامت آن ذاك بنشر نقافة

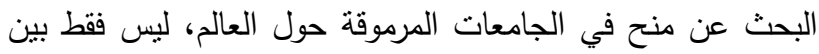

• المحور الثالث: محور دعم حوار السياسات، من خلال التشبيك

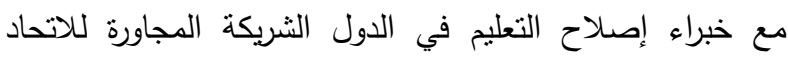
الأوروبي.

• أنشطة جين مونيه: والتي تهدف إلى تشجيع التدريس والبحث والتفكير في مجال دراسات الاتحاد الأوروبي في جميع ألتيع أنحاء العالم.

ويُعد برنامج Erasmus+ نتاج تكامل واندماج كافة برامج الاتحاد الأوروبي للنعليم العالي في السابق TEMPUS, Erasmus Mundus,...etc.

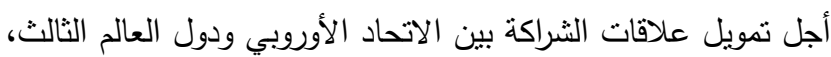

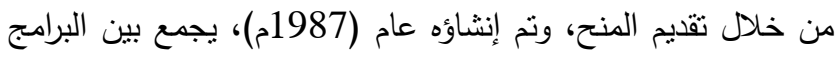
الحالية للوحدة الأوروبية للتعليم والتدريب والثباب والرياضة، والتي التيان

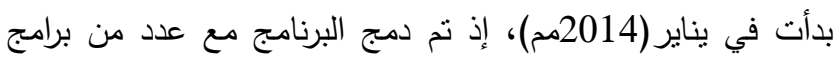

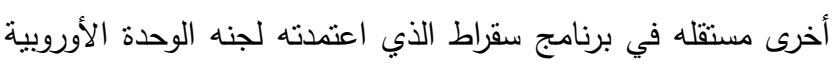

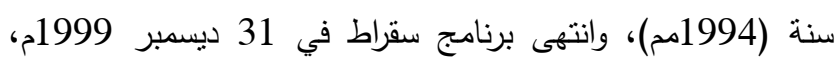

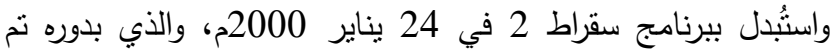
استبداله ببرنامج التعليم مدي الحياة 2013م-2007م، في 1

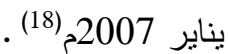

ويعود اسم البرنامج للفيلسوف الهولندي إيراسموا، الذي يُعرف

باسم خصم الدوغماتية، الذي عاش وعمل في أماكن كثيرة في أوروبا لتوسيع معارفه واكتساب معارف جديدة، ونرك نركته لجامعة بازل في سويسرا.

وأُنشئ البرنامج في الفترة 1981م-1986م، بعد نبادل الطلاب التجريبي، وعلى الرغم من أنه اعتُمد رسمياً لوقت قصير قبل بدء العام الفرام الدراسي 1987م-1988م، ولاتزال هناك إمكانية مشاركة(3,244) طالبا في برنامج إيراسموس في السنة الأولى، وفي عام 2006م كانت

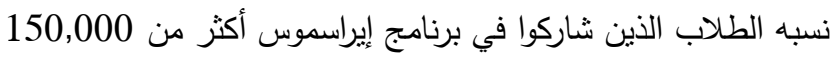

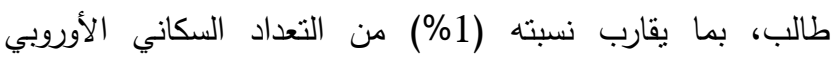
للطلاب، ونسبة أساتذة الجامعات الذين شاركوا في برنامج إيراسموس لـانه

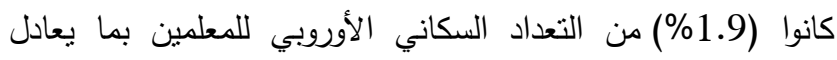
20.877 شخصا.

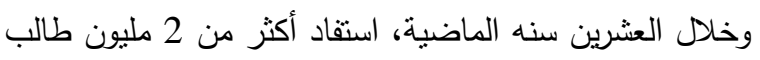
من منح إيراسموس، وبلغ عدد الطلاب المشاركين في البرنامج 3

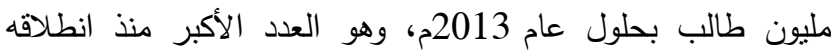
وبدئه بالعمل منذ عام 1984م حيث لا يدفع الطالب تكاليف الدراسة

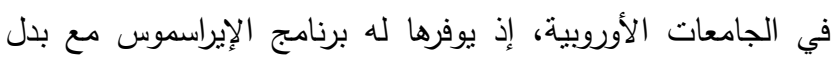
سفر شهري يختلف من بلد إلى بلد ومن جامعة إلى جامعة، ويتحمل الطالب فقط تكاليف الفيزا وتذاكر السفر والإقامة. وشجع البرنامج الأوروبي انتقال الطلاب ما بين الجامعات، وكنلك انتقال أعضاء الهيئة التنريسية، وإعداد الهناهج الدراسية 
5. تحسين كفاءات اللغات الأجنيية 6. نقل وتبادل الخبرات والثقافات وأفضل الممارسات.

وفيما يلي سرد لبعض الإحصائيات الخاصة بنشاطات الجامعة

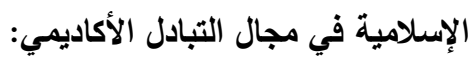
1. صلت الجامعة الإسلامية على تمويل لستة مشاريع ضمن برنامج إراسموس مندوس (Erasmus Mundus) بالثراكة مع 70 جامعة محلية وإقليمية ودولية، والتي ينم تتفيذها خلال الفترة

$$
2012 \text { وحتى } 2017 .
$$

2. انتركت الجامعة بما يزيد عن 12 مشروعاً للتبادل الأكاديمي الدولي، ممولة من قبل برنامج إراسموس بلس (Erasmus+)

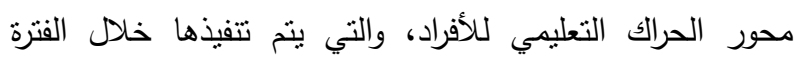
.2019-2016

3. اشتركت الجامعة الاسلامية ببرنامج التبادل الثقافي التركي مولانا مع 6 جامعات تركية، والتي ينم تتفيذها في الفترة 2013-2021.

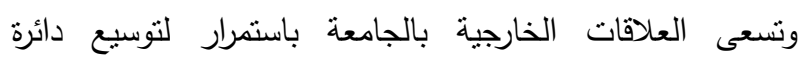

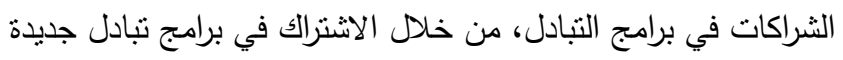
مع دول وجامعات أوروبية جديدة، والجامعة الإسلامية بغزة

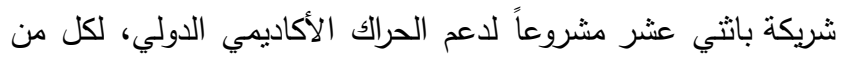

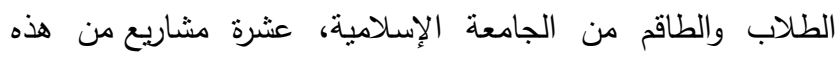

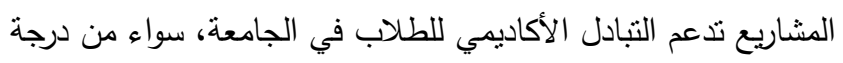
البكالوريوس أو الماجستير ، والتي يمكن تلخيصها بالجدول التالي: لإني

\begin{tabular}{|c|c|c|c|c|c|}
\hline \multirow[b]{2}{*}{ آخر مو عل التقيم الطلب } & \multicolumn{2}{|c|}{ قيمة الهندة } & \multirow[b]{2}{*}{ هدة الثبادل } & \multirow[b]{2}{*}{ الدولة } & \multirow[b]{2}{*}{ الجامعة المستضيفة } \\
\hline & تكاليف سفر & تكاليف الميشة & & & \\
\hline 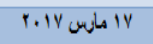 & Aيو Aيt. & A يونl & أمهرا & بريطنيا & جامعة جلاسجر \\
\hline T & estor. & Aئ... & مه مهن & إبباتيا & جامعة برشلمية \\
\hline- & . & (A... & مهند & إبباتيا & جامعة ساتثياغو دي كممبيستيلا \\
\hline- & esor. & - Aي... & أمهرا & إبباتيا & جامعة ألماريا \\
\hline- & Pيو & (A... & م مهد & إباتيا & جامعة غزناطة \\
\hline - & P rVo & (A... & O مهند & ت تركيا & جامعة الثرق الأوسط الثقتية \\
\hline - & Nor. & No. & مه مهن & |iliti & جامعة تامبرا \\
\hline - & Th" & Tivo & مه مهن & بوبلتا & جامعة الاقتصلاد في كاتوفيتشبي \\
\hline - & " & 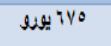 & مه مهر & بوباتلا & جامعة وانسو \\
\hline - & Th" & A A A A & T 19 & اليطاليا & جامعة لاكويلا \\
\hline
\end{tabular}

المشاريع المشاركة بها الجامعة الإسلامية لدعم التبادل الأكاديمي(21)

التعاون الدولي بين الجامعة الإسلامية والجامعات

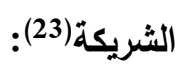

وخلال العام 2017 نوسعت رقعة شراكات الجامعة مع أكثر من 130 جامعة اوروبية نتيجة مشاركتها في 40 مشروعاا ثنائي

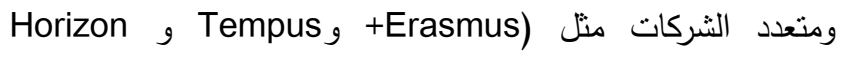

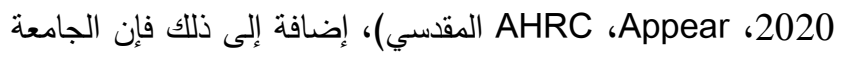

كوادر الجامعة ولكن أيضاً لخريجي الجامعة وخريجي الجامعات

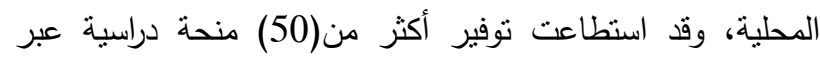

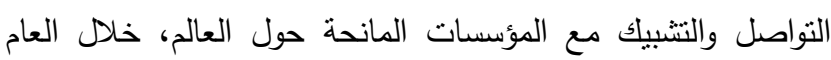

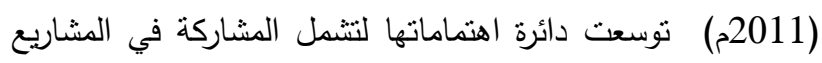

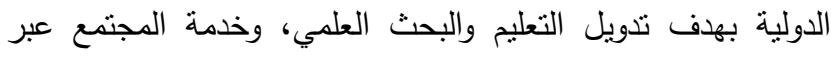

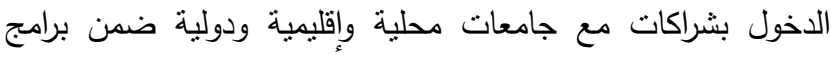

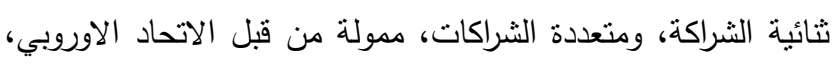
ودول الاتحاد الأوروبي (21).

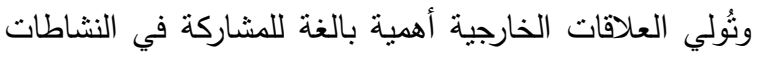

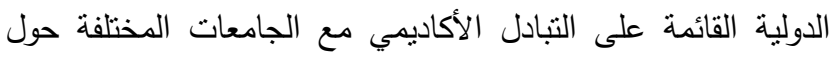

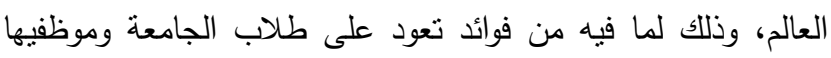

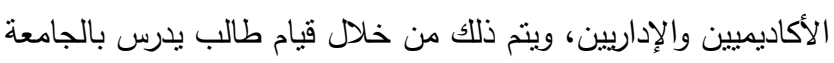

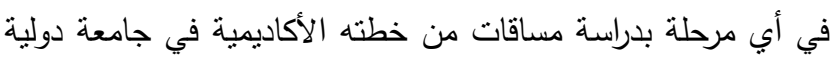
لها شراكة مع الجامعة، على أن يتم معادلة المساقات التي نجح فيها

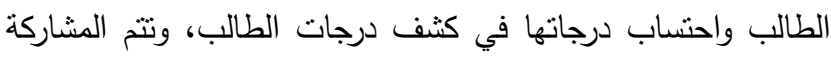

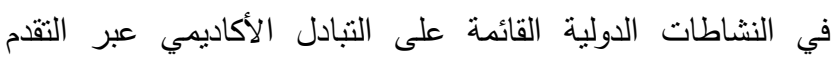

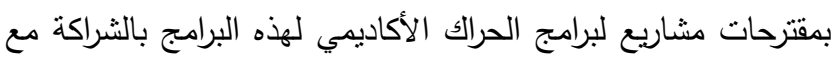
الجامعات المختلفة في مختلف دول العالم مثل دول اوروبا وتركيا وماليزيا، ومن أثنهر البرامج التي تمول التبادل الأكاديمي والتي نفذت دولت دان

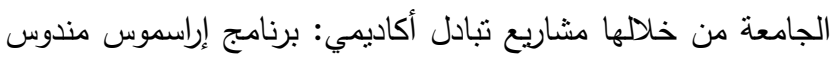
(Erasmus Mundus)

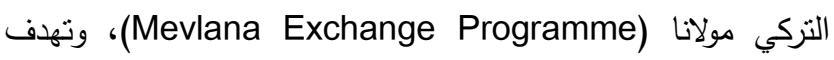
برامج التبادل الأكاديمي بالدجمل إلى التبادل الثقافي ونقل الخبرات بين الجامعات والدول المختلفة لتحسين القدرات المؤسساتية في هذه الهي الدول، كما تهدف أنشطة التبادل الأكاديمي إلى تحقيق النتائج التالية:

$$
\text { أولاً: على مستوى الطلبة: }
$$

1. تحسين الأداء والتعلم بالإضافة إلى زيادة التمكين الذاتي والتقة بالنفس. 2. تعزيز فرص العمل وتحسين آفاق التطور الوظيفي. 3. زيادة روح المبادرة وريادة الأعمال. 4. 5 3. تحسين كفاءات اللغات الأجنبية 5. نعزيز الوعي بين الثقافات ومشاركة أكثر نشاطاً في المجتمع. ثانياً: على مستوى الطاقم: 1. تحسين الكفاءات المهنية وزيادة فرص التطوير الذاتي والوظيفي. 2. فهم أوسع للممارسات والسياسات والأنظمة في مجال النطيرة التعليم والتدريب في مختلف البلدان. 3. زيادة القدرة على احداث التغييرات في مجال التحديث والانفتاح الدولي داخل المؤسسات النعليمية 4. زيادة التفاهم والتجاوب على التتوع الاجتماعي واللغوي والثقافي. 
الإسلامية شريك مع أكثر من 66 جامعة فلسطينية وعربية في كلّ من 1 1. اسم المشروع: زيادة توافق المؤسسات لأكاديمية نحو هندسة

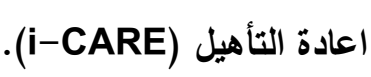

• جهة التمويل: إراسموس بلس الأوروبي محور بناء القدرات

م فريق المشروع: من الجامعة الاسلامية: د. عمار أبو هدروس -ـ.

طالب الريس-د. محمد الحنجوري، د. محمد كريزم.

•

الأزهر -منسق المشروع الرئيسي-، 2. 2.

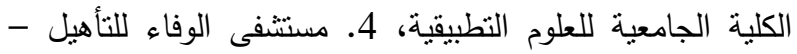

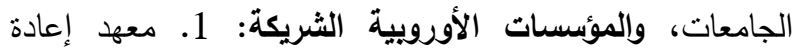

التأهيل الجامعي -جمهورية سلوفينيا، 2. جامعة روسه-بلغاريا،

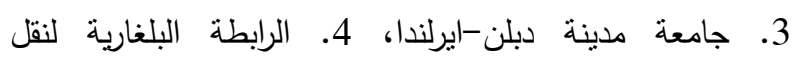

التكنولوجيا والابنكار بلغاريا.

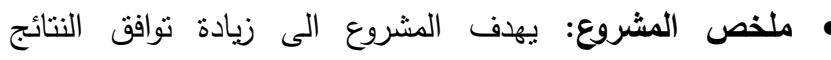
الأكاديمية الفلسطينية مع قدرات مقدمي خدمات إعادة التأهيل

الفلسطينية نحو تحديد مكانة تكنولوجيا إعادة الثأهيل.

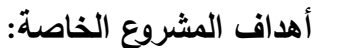

تطوير العديد من الدورات التدريبية في مجال الصحة وتكنولوجيا إعادة

$$
\text { التأهيل لتعزيز الممارسات العملية. }
$$

ل تطوير قطاع التعليم العالي وبناء قدرات الكوادر الأكاديمية في مجال الصحة وإعادة التأهيل.

تشجيع تعلم الخدمة من خلال نطوير نظام تعليمي للتكنولوجيا

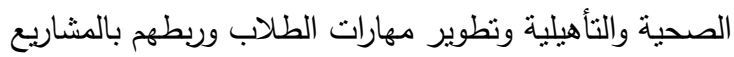

التعليمية التي تمثل احتباجات مجتمعية حقيقية.

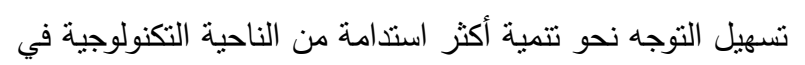

$$
\text { فلسطين والبلدان الثريكة. }
$$

ل تعزيز الوعي المجتمعي وزيادة أثره على تكنولوجيا إعادة التأهيل.

$$
\text { • فترة تتفيذ المشروع: 2017/10/15 حتى 2020/10/15 }
$$

• اسم المشروع: أكاديمية لاعم المدن الذكية في فلسطين

.(esco)

• جهة التمويل: برنامج إراسموس+ الأوربي -محور بناء قدرات مؤسسات التعليم العالي (CBHE).

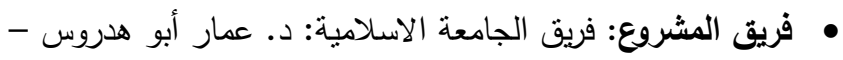

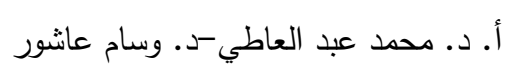

• المؤسسات الثريكة: الجامعات والمؤسسات الفلسطينية الثريكة:

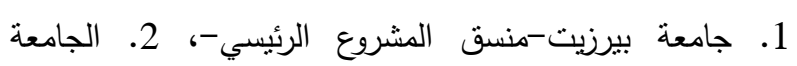
الاسلامية، 3. جامعة القس، 4. وزارة ليرنس الاتصالات وتكنولوجيا المعلومات الفلسطينية، 5. بلدية رام الله. - الجامعات الأوروبية
الأردن ولبنان وسوريا ومصر وتونس. كما أن الجامعة الاسلامية ندير 3 مشاريع موضحة كالآتي:

1. تطوير مراكز البحوث الإدارية والاقتصادية في الجامعات الفلسطينية (BERC)للفترة (2015-2018) الممول من قبل فيل فئل برنامج إراسموس بلس -محور بناء القدرات-، والذي يتم تتفيذه

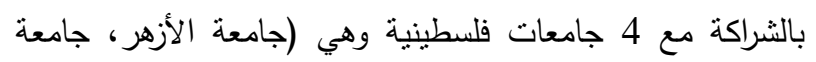
بيرزيت، جامعة القدس المفتوحة، الكلية الجامعية للعلوم التطبيقية)، 4 جامعات أوروبية وهي (جامعة L'Aquila لا كويلا -ايطاليا،

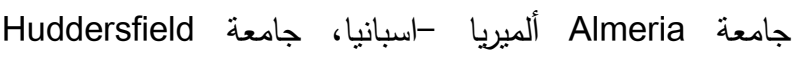
هدرسفيلد-بريطانيا، المعهد الملكي للتكنولوجيا KTH-السويد). 2. إدارة مخرجات البحث العلمي من خلال المستودعات المؤسية لمانية متاحة الوصول في مؤسسات التعليم العالي الفلسطينية (ROMOR)

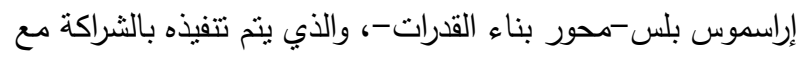

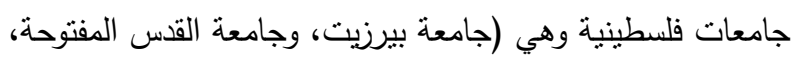

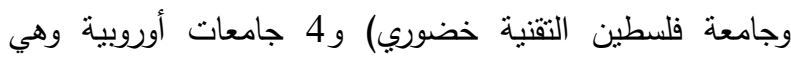
(جامعة فينا التقنية في النمسا، وجامعتا جلاسكو وبرايتون في بريطانيا، وجامعة بارما في (يطاليا).

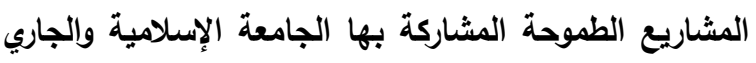

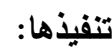

في ذات السياق قمنا بعقد مقابلة مع الدكتور عمار أبو هلدرس وهو أستاذ مشارك في كلية الهندسة في الجامعة الإسلامية، وضمن المنابل

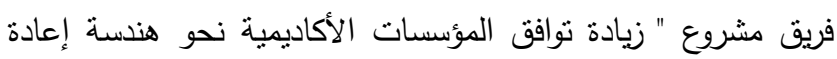

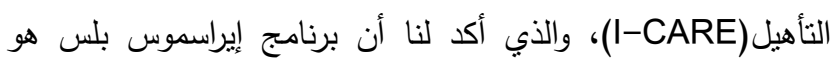

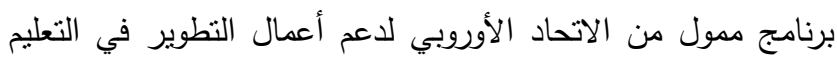
العالي بالدول الثريكة في شرق أوروبا ووسط آسيا ودول غرب البات البلقان

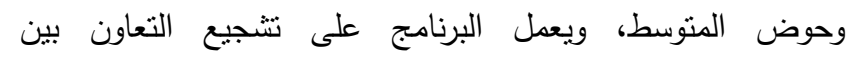

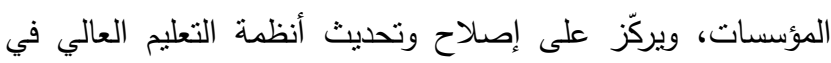

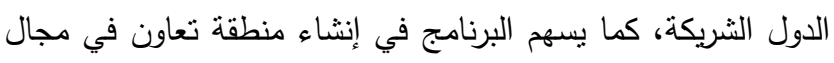

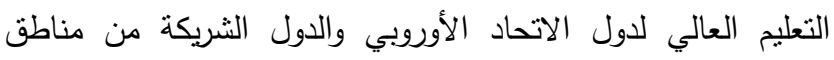

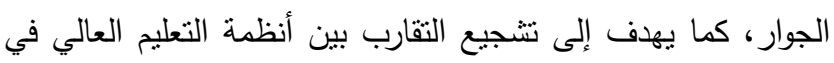

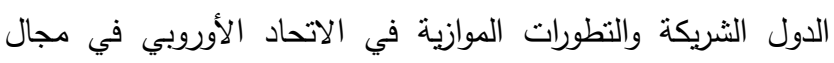
التعليم العالي، بالإضافة إلى نتجيع التعاون بين المؤسسات المختلفة،

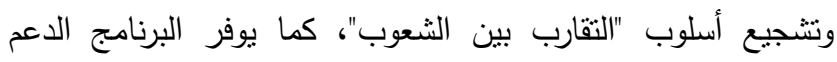
لتجمعات مؤسساتية تتكون في الغالب من الجامعات أو الاتحادات

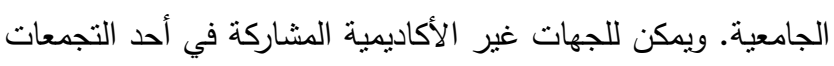

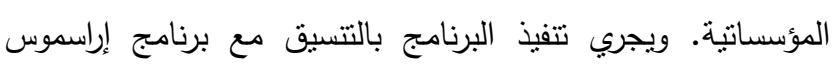

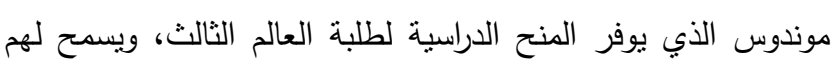

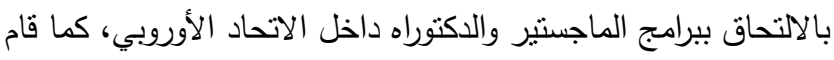

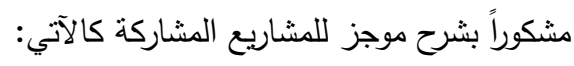


وضع إطار وهيكل إداري واضح وفعال، وكنلك تقوية العلاقات مع مختلف أصحاب المصلحة والثفافية في أنشطة التخطيط والنطوير وضير الاستراتيجي.

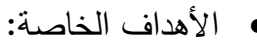
حلق بيئة مواتية لاعتماد نظام حوكمة جيد. ل إنشاء هياكل حوكمة وادارة فعالة. ل تحفيز الحكم الذاتي والمساءلة. $\checkmark$ تعزيز الروابط مع مختلف أصحاب المصلحة. • فترة تتفيذ المشروع: 2016 إلى 2019م. كما أثنار الأستاذ الدكتور حاتم حماد رئيس إدارة تكنولوجيا المعلومات ونائب الرئيس المساعد لتكنولوجيا المعلومات، إلى أنّا برنامج إيراسموس+، عمل على تطوير ونتمية الكوادر الأكاديمية والإدارية، كما شجع على التثبيك الأكاديمي وتحسين سمعة الجامعة إلتريك

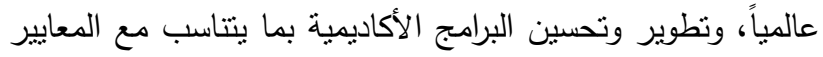
الدولية وأسواق العمل المحلية والعالمية، والارتقاء بمستوى البحث

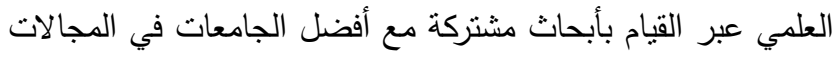
المختلفة، كما أسهم تدويل الجامعة الإسلامية في إكسابها صبغة بابحة عالمية، وتحقيق مكانة علمية مرموقة، واكسابها قدرة تتافسية في ظل ما يواجهها من تحديات. ولعل من أهم بنود هذه المشاريع هو الزيارات

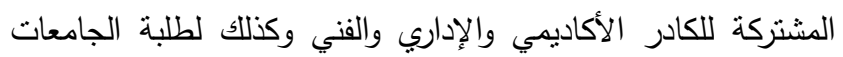
سواء في مراحل التعليم الجامعي البكالوريوس أو الماجستير، علما بأنه

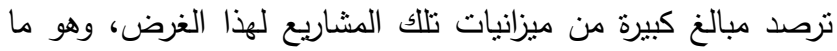
يتيح تبادل الثقافات والمعارف والخبرات، والمناهج، من خلال الزيارات

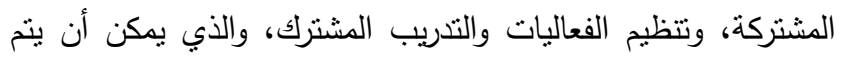
بطرق مباشرة أو غير مباشرة، كما تؤسس تلك الزيارات لعلاقات مشتركة بين الأطراف، بين الجامعات والمعاهد ومؤسسات التعليم

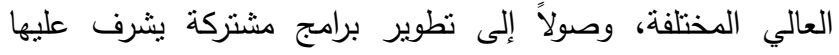
الأطراف المتعاقدة كافة، مع وضع الضمانات لإبقاء عملية التطوير مستمرة ومتواصلة، وحدثتا عن المشروع بقوله:

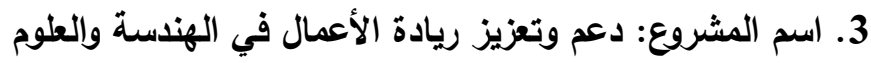
والرياضيات وتكنولوجيا المطومات في الجامعات الفلسطينية .(FESTEM)

• جهة التمويل: برنامج إراسموس بلس-محور بناء قدرات مؤسسات التعليم العالي.

• فريق المشروع: فريق الجامعة الاسلامية: أ. د. حاتم حماد، م. علاء أحمد.

• المؤسسات الثريكة: المؤسسات الفلسطينية الشريكة: 1. الجامعة الاسلامية، 2. جامعة بيرزيت، 3. جامعة بوليتكنك فلسطين، 4.
الثريكة: 1. جامعة مالقة-أسبانيا، 2. جامعة روما سابينزاايطاليا، 3. جامعة سالفورد-بريطانيا.

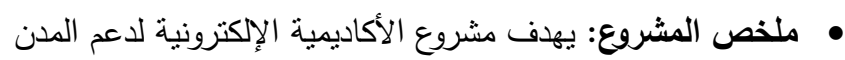
الذكية في فلسطين (Esco) إلى بناء القدرات وتعزيز مهارات

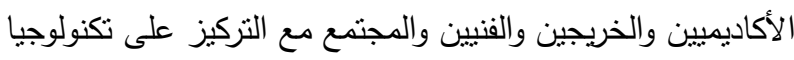
المعلومات والاتصالات والثبكة الذكية لدعم إنثاء وتشغيل المدن

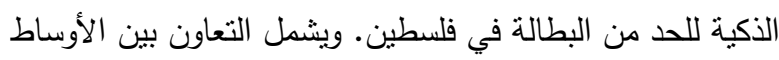

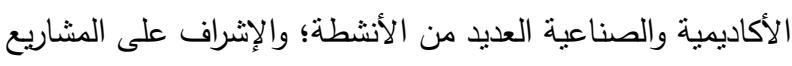

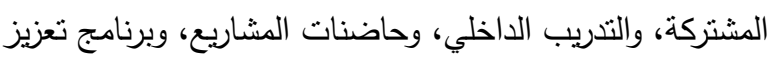
روح المبادرة والإلهام الابتكار والمشاريع. فترة المشروع: 2017/10/15 حتى 2020/10/15

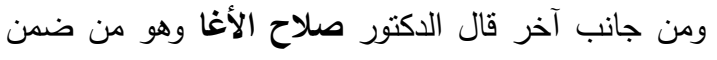
فريق مشروع "تحسين إدارة الجامعات في الجامعات الفلسطينية UniGov

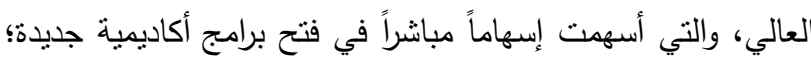

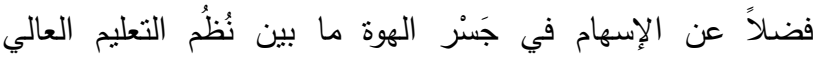
الفلسطينية والنظم التعليمية في الدول العربية والأوروبية، وتعزيز مفهوم عولمة التعليم، وجدير بالذكر أن هذا البرنامج يُعنى في بناء قدرات مؤسسات التعليم العالي وتعزيز فرص مشاركة الطلبة وكوادر بادير الجامعات الإدارية والأكاديمية في التبادل المعرفي والمهني فلسطينياً وإقليمياً ودولياً، أما عن المشروع فتحدث والاديائلاً:

2. اسم المشروع: تحسين إدارة الجامعات في الجامعات

\section{UniGov-القلسطينية}

• جهة التمويل: المفوضية الأوروبية عبر برنامج إراسموس بلس محور بناء قدرات مؤسسات التعليم (CBHE-Erasmus Plus) العالي. • فريق المشروع: د. صادق عبد العال، د. حاتم العايدي، د. بسام السقا، د. صلاح الآغا. • المؤسسات الشريكة: الجامعات القلسطينية: جامعة النجاح الوطنية (منسق المشروع الرئيسي)، الجامعة الإسلامية، جامعة بيرزيت،

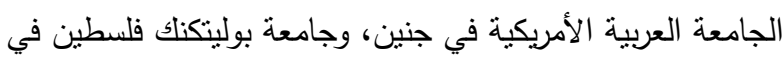
الخليل، وأربع جامعات أوروبية، هي: جامعة إيفورا في البرتغال،

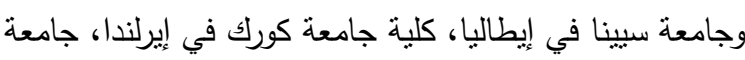
ليوبليانا في سلوفينيا، بالإضافة إلى اتحاد الجامعات المتوسطية.

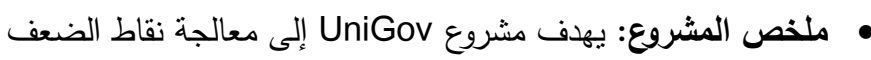

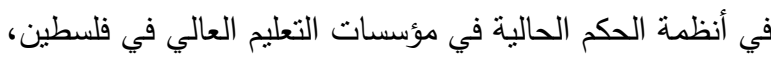
عن طريق اجراء دراسات مقارنة مع الجامعات الأوروبية المتميزة. وسيعمل المشروع على خلق بيئة ملائمة لتنبي ممارسات الحوكمة، 
أهداف التتمية المحدة لكل بلد، مما سيساهم بشكل كبير في تطوير

التعليم والبحث العلمي في جامعة الأقصى.

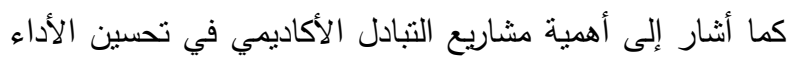

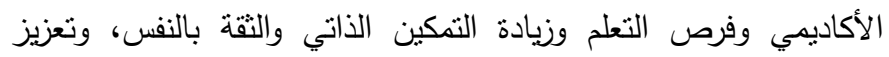
فرص العمل وتحسين آفاق التطور الوظيفي، إضافة إلى تحسين كفاءات اللغات الأجنبية، بالإضافة إلى تعزيز الوعي والتفاهم بين الثقافات ونقل

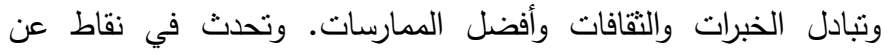
المشروع الذي هو ضمن فريقه فأوجز بقوله:

• اسم المشروع: تعزيز القدرة البحثية الوطنية على السياسة وحل

$$
\text { النزاعات والمصالحة. }
$$

• جهة التمويل: برنامج إراسموس+ (المفوضية الأوروبية) محور بناء قدرات بناء التعليم العالي.

• • فريق المشروع: د. وليد الددلل د. وائل الداية م. أماني المقادمة. • المؤسسات الثريكة: الجامعات الفلسطينية: 1-الجامعه العربية

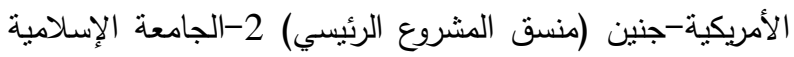

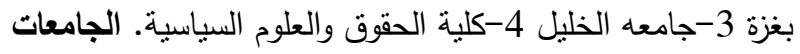

الأورويية: 1-جامعة ينا: المانيا 2-جامعة غرناطة اسبانيا.

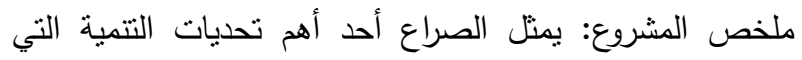

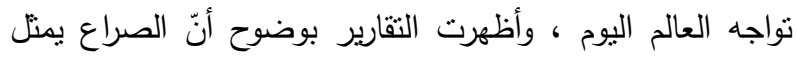
عائقًا رئيسيًا أمام التتمية البشرية والازدهار في فلسطين، حيث إنه مضى جيل على توقيع اتفاقية أوسلو بين فلسطين و (إسرائيل.)

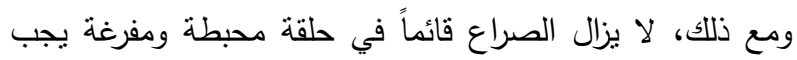
كسرها، والا فإن إمكانات التتمية للأجيال المقبلة سنظل مقيدة بالإضافة إلى ذلك زادت وجهات النظر المنباينة للأحزاب السياسية

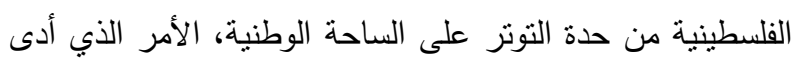

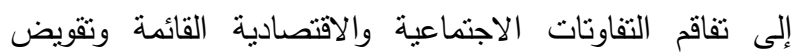
التماسك الاجتماعي.

ويعد هذا المشروع أولوية استراتيجية لفلسطين، ويتوافق بشكل جيد مع أجندة البحث الوطنية، ويسعى المشروع إلى "تحسين إدارة

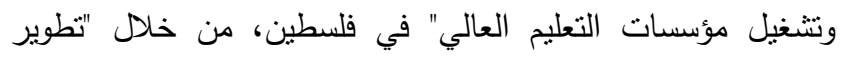

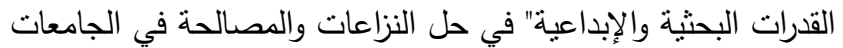

الفلسطينية.

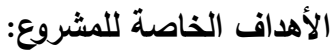

- نطوير مهارات الباحثين وقدراتهم على حل النزاعات والمصالحة. - تعزيز الثراكات الاستراتيجية والتواصل مع المراكز الرائدة لحل النزاعات، والاستراتيجيين والمؤسسات السياسية. -تشجيع البحوث متعددة التخصصات المتعلقة بحل النزاعات والمصالحة (منل العلوم السياسية والعلاقات الدولية والسياسة والقانون).

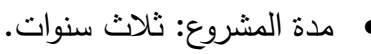

جامعة فلسطين النقنية - خضوري، 5. المجلس الأعلى للإبداع والتميز، 6. شركات ناشئة عدد 3. الجامعات الأوروبية الثريكة: 1. جامعة سيجن-ألمانيا (منسق المشروع الرئيسي)، 2. كوبنهاغن-الدنمارك، 3. جامعة ميدلسكس -بريطانيا.

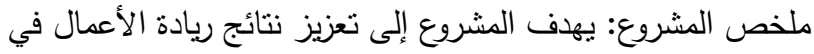
برامج العلوم والتكنولوجيا والهندة والرياضيات في مؤسسات التعليم

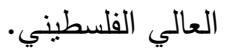

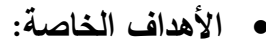

ل تقيم النظام داخل أربع جامعات فلسطينية لتشجيع تعليم ريادة الأعمال في برامج العلوم والتكنولوجيا والهنسة والرياضيات، من أجل المساهمة في النظام المحلي لرواد الأعمال. ل وضع مفاهيم لتعلم التلمذة الصناعية والتدرب داخل القطاع الخاص. لرعاص. تعزيز الوصول إلى التمويل للثركات الناشئة والمنشأة حديثًا وإثراك

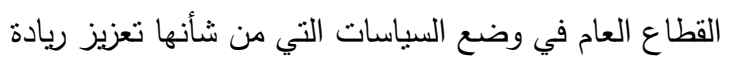

$$
\text { الأعمال في التعليم العالي. }
$$

ل نطوير نموذج يدمج البرامج الأكاديمية في STEM في الجامعات

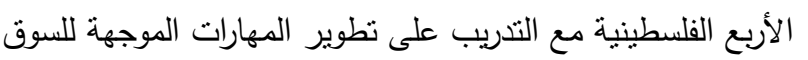
والتدريب العملي على رأس العمل في الثركات المبتدئة.

ل تقليص الفجوة بين التعليم والصناعة وضمان تدفق أكثر سلاسة للمعرفة وأفكار الأعمال من طلبة. الجامعات. • فنرة تنفيذ المشروع: 3 سنوات، أكتوبر 2017 وحتى أكتوبر 2020.

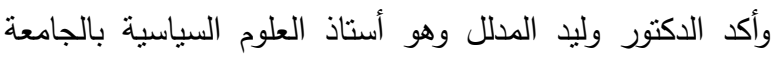

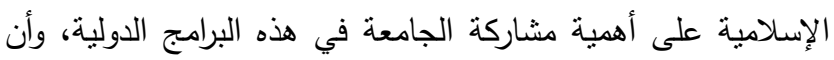

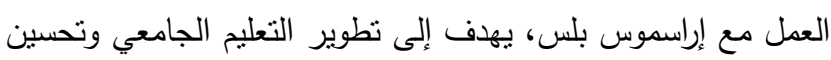
الأنظمة والسياسات، وطرق التدريس، وتحسين نظم الإدارة والقيادة والمشاركة الهجتمعية، كما يتم التركيز على تطوير مهارات الكادر

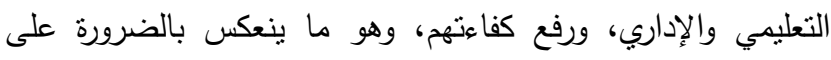

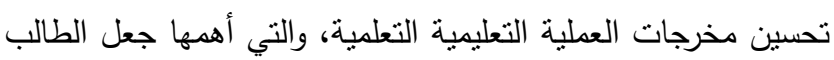

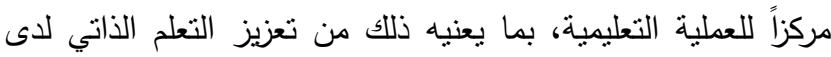
الطلبة، ورفع كفاءتهم من خلال الزيارات المشتركة التي يشارك فيها

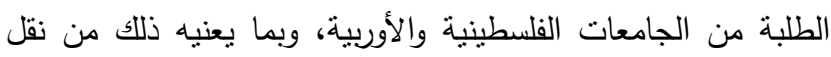
الخبرات والمعلومات والمهارات، ومطابقتها لسوق العمل. كما أنشار

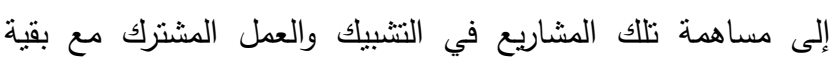
الجامعات، ومؤسسات المجتمع المدني، وهو ما سيدعم الجامعة ويحسن من جودة التعليم ونواتج التعلم. وأثار إلى دور هذا البرنامج في بناء علاقات دولية وشراكات

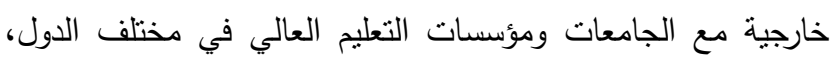
الأمر الذي من شأنه تحسين القدرات في مؤسسات التعليم العالي

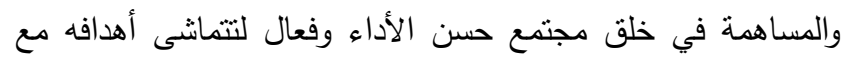




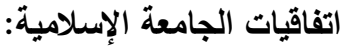

نم توقيع ثلاث اتفاقيات تعاون بين الجامعة الإسلامية

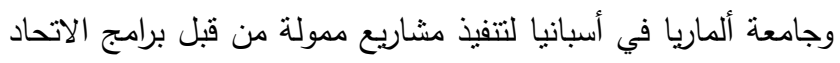
الأوروبي موضحة كالتالي: - الئ

• اتفاقية تعاون بين الجامعة الإسلامية وجامعة ألماريا بتاريخ 2015/12/1 حنى 2018/12/1 ونأتي هذه الاتفاقية ضمن مشاريع إراسموس بلس الأوروبي المحور الثاني - بناء القرات في

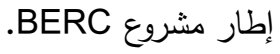

• اتفاقية تعاون بين الجامعة الاسلامية وجامعة ألماريا بتاريخ 2015/10/7 حتى 2017/7/1 وتأتي هذه الاتفاقية ضمن مشاريع إراسموس بلس الأوروبي في المحور الأول لدعم الحرالك

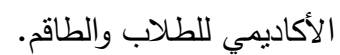

• اتفاقية تعاون بين الجامعة الإسلامية وجامعة ألماريا بتاريخ 2012/12/3حتى 2017/12/3 وتأتي هذه الاتفاقية ضمن

\section{مشروع.PHOENIX.}

كما تم توقيع مذكرة تعاون بين الجامعة الإسلامية وجامعة

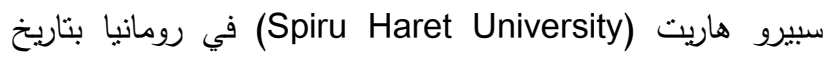
2015/3/2 واشتملت الاتفاقية على مجالات التعاون التالية: • التبادل الأكاديمي لطلبة مرحلة البكالوريوس وطلبة الدراسات العليا. • تطوير برامج أكاديمية مشتركة. برامج التبادل للأكاديميين والإداريين. المجالات والمشاريع البحثية المشتركة.

عقد ورش عمل ومؤتمرات مشتركة. • • تبادل الأوراق البحثية والمنشورات العلمية. تتفيذ برامج أكاديمية بالثراكة بين الجامعتين.

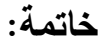

التجديدات التربوية لغة العصر وأداته الرئيسة في الإصلاح

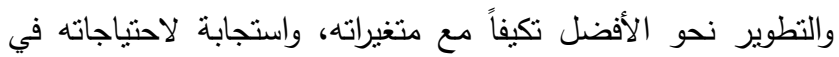
ظل التتافسية والتصنيف العالمي، والدعوة السائدة نحو التدويل والانتقال السلس للطلاب لاستكمال دراستهم في أي دولة في العالم، وكذلك التوجه المتسارع والحتمي نحو الجودة والاعتماد في النعليم العالي، وفي ظل ما يعانيه التعليم العالي في المنطقة العربية من التهن مشكلات وتحديات مشتركة، يشهذ عالمنا المعاصر نطوراً كبيراً، وتحولات جذرية في أهداف وسياسات النظم النعليمية منأثرة بضغوط

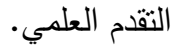

ومع الاعتراف بأهمية دور مؤسسات التعليم العالي في خدمة تلبية الاحتباجات المجتمعية والمؤسسية المتتوعة، إلا أن ذلك وحده غير كاف، إذ نوجد ضرورة تنظيمية لتحديد الدداخل التي يمكن أن تستخدمها هذه المؤسسات في التطوير لتحسين وتتمية الموارد البشرية
وتحدث الدكتور وائل الداية وهو محاضر بكلية التجارة قسم إدارة

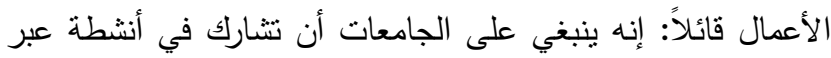
الحدود الوطنية، وكذلك على المستوى العالمي، من خلال نتادل الطلاب والباحثين، والانخراط في مشاريع في مجالات التعليم والبحوث مع المؤسسات في الدول الثريكة في مناطق أخرى من العالم، وفي ظل تزايد ثراء تتوع قوة العمل في العالم، أصبح لزاماً على المؤسسات ضرورة التوجه للاستفادة القصوى من أهم مورد، ألا وهو القوى العاملة وما تملكه من مهارات، وذللك لتحقيق النجاح والحفاظ على الميزة التتافسية، وبالتالي تزداد الحاجة إلى نوسيع نظرتنا للقوى العاملة،

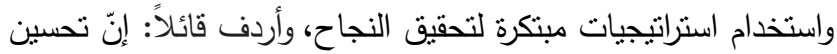
مخرجات العملية التعليمية بما بشمل تحسين مستويات الطلبة من الناحية المعرفية والمهارية، ومراعاة منطلبات سوق العمل، سوف لفئل يحسن بالضرورة فرص الطلبة في نيل وظائف جادة ومميزة، بهذا نستطيع القول إنّ برنامج إيراسموس+ بيساهم بدرجة ما في تحسين فرص النوظيف والعمل لخريجي الجامعات، وإن كان الأمر برمته متعلقا ومنأثرا بسوق العمل الفلسطينية المحدودة والدحاصرة بسبب الظروف الخاصة التي تعيشها فلسطين وقطاع غزة على نحو خاص. وتحدث عن المشروع المشارك في فريقه قائلاً: 4. اسم المشروع: تطوير قدرات مراكز الأبحاث الإدارية والآتصادية فئهات في مؤسسات التعليم العالي في فلسطين والذي تولت جهة تمويله المفوضية الأوروبية عبر برنامج إراسموس بلس (Erasmus Plus)، وتكوّن فريق عمله من: د. وائل الداية، د. خالد دهليز ، د. وسيم الهابيل، م. أماني الدقادمة، أ. هديل شاهين، أما المؤسسات الثريكة فيه فهي: الجامعات الأورويية: University of ‘University of Huddersfield-UK KTH ‘University of L'Aquila-Italy ‘Almería-Spain Royal Institute of Technology-Sweden الجامعات المحلية مثل: الجامعة الإسلامية بغزة، جامعة الأزهر،

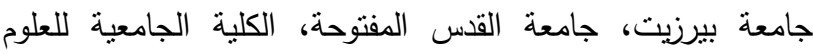
التطبيقية، وهدف المشروع إلى تحسين البيئة البحثية في المجالات

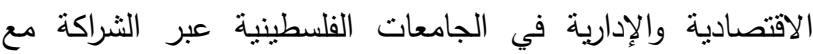
الجامعات الأوروبية، وتطوير وتعزيز مبادئ الجودة في مراكز البحوث الاقتصادية والإدارية في الجامعات الفلسطينية، كذللك بناء قدرات الكوادر العاملة في مراكز البحوث الاقتصادية والإدارية في الجامعات الفلسطينية، ونظوير شبكة من مراكز البحوث الاقتصادية

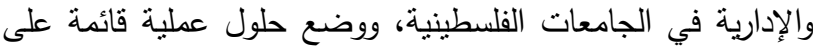
البحث العلمي للتحديات التي تواجه المجتمع، وتحسين الجانب

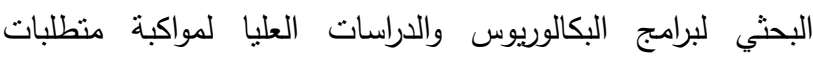

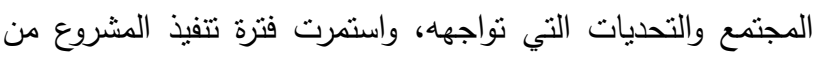
.2018-2015 
المجال لدخول أسواق العمل المحلية والعالمية، لهذا كان لابد مّمن

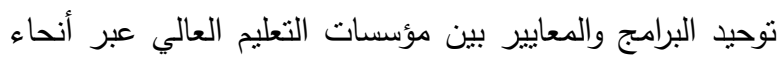

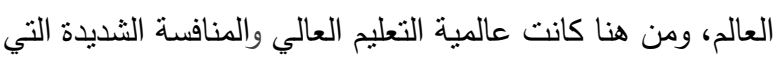
فرضت لنوفير خدمة تعليمية ذات جودة عالية.

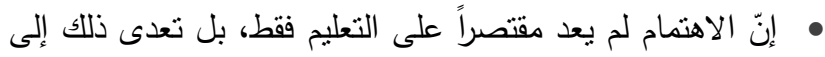
جودة التعليم والاستثمار فيه، ويعود ذللك إلى الاهتمام المتزايد بنفقات تكلفة العائد من التعليم.

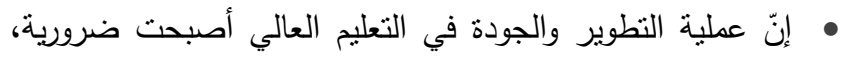
لما تكتسبه مؤسسات التعليم العالي وخريجوها من ميزة تتافسية، سواء على المستوى المحلي أو على المستوى الدولي.

\section{التوصيات}

في ضوء نتائج الدراسة ومناقشتها يمكن اقتراح التوصيات

1. المواظبة على نتبع مواقع الممولين ومواقع البرامج المعروفة،

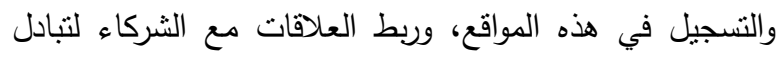

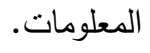

2. يتعين على الجامعات نشر المعلومات حول مختلف برامج التعاون، وحول مهامها وأنشطتها، وذللك عبر بوابتها الإلكترونية،

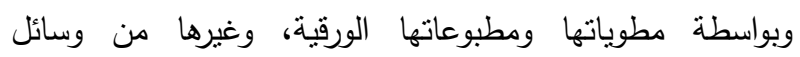

الاتصال المختلفة.

3. المساهمة في تتمية فكر ووعي طلابي متعدد الثقافات، والخروج

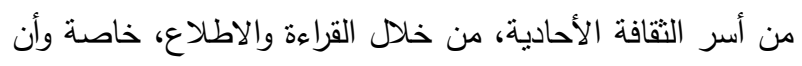

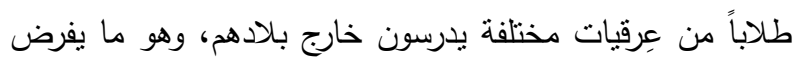

$$
\text { تغييراً في المناهج لصالح التعدد الثقافي. }
$$

4. نشر المعلومات المتعلقة بطلبات تقديم المقترحات وبرامج التعاون،

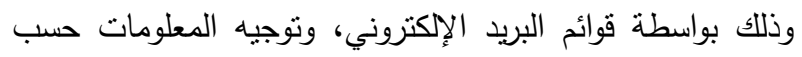

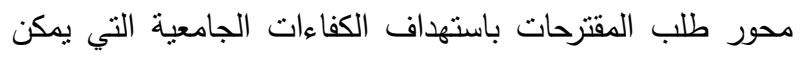

$$
\text { أن يهمها محور ما. }
$$

5. لن تتحقق الريادة العالمية للجامعات دون أن يكون لها روية استراتيجية عالمية، وأهداف ذات صبغة دولية، تعمل على إضفاء البُعد الدولي على أنشطتها في البحث العلمي والتدريس وخدمة

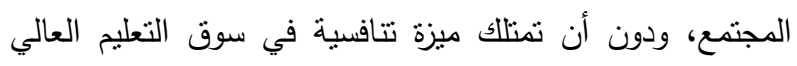

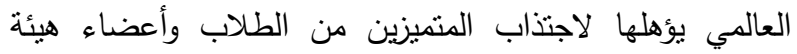

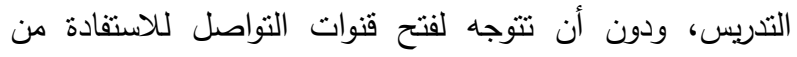
خبرات الجامعات العالمية عن طريق التعاون الدولي ممثلاً ببرامج لتونج التوأمة والتبادل العلمي والثراكات البحثية.
وتلبية الاحتياجات من خلال تنظيم البرامج التعليمية والتدرييية المختلفة، حيث نظم الاتحاد الأوروبي برامج منتوعة هدفت مكافحة

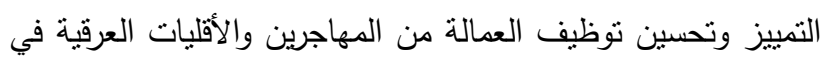
أوروبا. وتُعد برامج التمويل الخارجية للمشاريع المشتركة نوعا من رئ

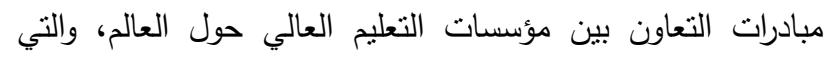
أنشأتها الجهات المانحة لتعزيز مؤسسات التعليم العالي في دول العالم التئي

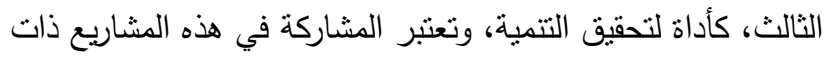

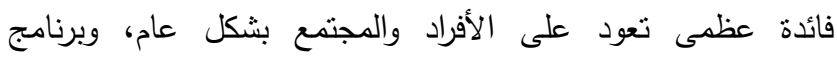
Erasmus

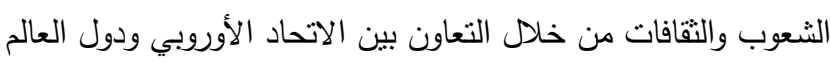

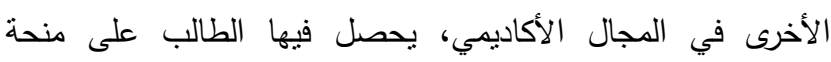
خاصة، يدرس فصلا دراسيا أو فصلين في جامعة غير جامعته، وذللك في إحدى الدول الأوروبية، أو القيام بدورة تدريب في شركة أجنيية،

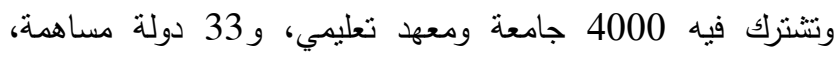

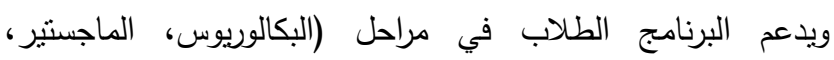
الدكتوراه)، وأعضاء الهيئات التدريسية، ويجب على على الطالب الذي يريد

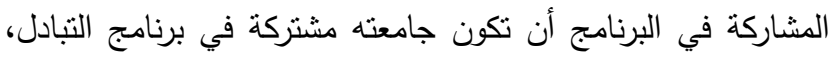

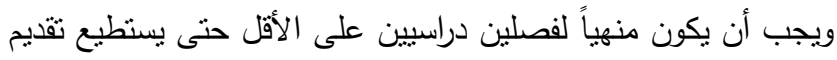

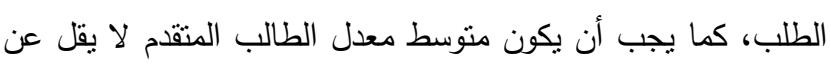

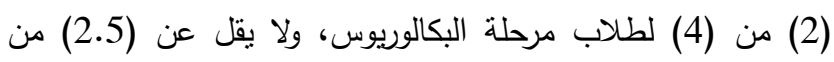
(4)، لطلاب مرحلة الماجستير والدكتوراه، ولا يجوز لطلاب التعليم

$$
\text { المفتوح التقدم للبرنامج. }
$$

\section{نتائج الدراسة}

\section{توصلت الدراسة إلى عدة نتائج أهمها:}

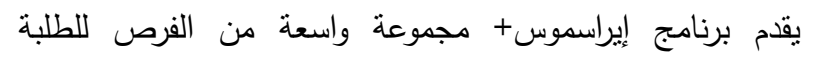

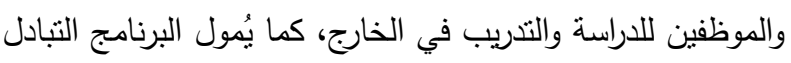

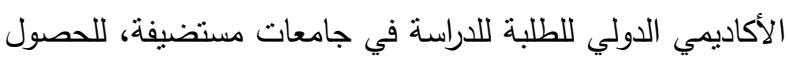
على درجات الماجستير والدكتوراه الكاملة، كذلك يمول تبادل التادل موظفي الجامعات مما بسمح لهم بالتدريس أو التدريب في الخارج لهات

$$
\text { في الجامعات الثريكة. }
$$

• خطة التمويل الخارجي للمشاريع المشتركة هي مبادرة تعاونية بين

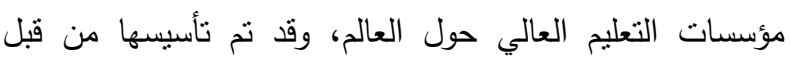
المانحين لتقوية مؤسسات التعليم العالي في دول العالم الثالث

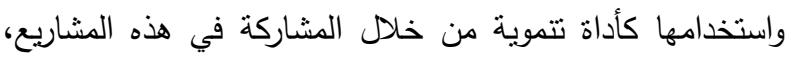

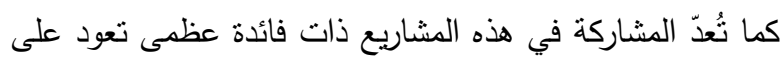

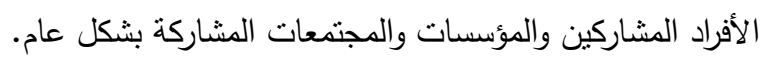

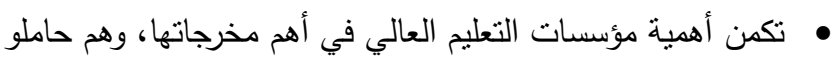
الثهادات المستقفيدون من العطلية التعليمية، وذلك بتزويدهم

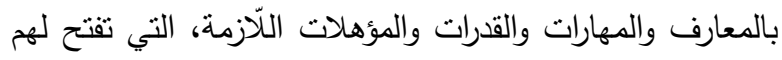


10. European Commission, Erasmus+ Programme Guide, 2019, version2 .

11. European Commission, International Monitor, Ministry of Education Agency for Planning and Information, Education Observatory, No 38, pp. 45-40, Belgium.2014 .

12. External Relations Bulletin, Islamic University, Gaza, 2015.

13. External Relations, "Frequently Asked Questions, International Exchange within the European Erasmus Plus Program", the Islamic University, Gaza, Retrieved on 21/3/2021, from: https://exrelation.iugaza.edu.ps/ar/\%D8\%A7\%D9 \%84\%D8\%AA\%D8\%A8\%D8\%A7\%D8\%AF\%D $9 \% 84-$

\%D8\%A7\%D9\%84\%D8\%A3\%D9\%83\%D8\%A7 \%D8\%AF\%D9\%8A\%D9\%85\%D9\%8A

14. French Diplomacy, Retrieved on 22/3/2021, from https://www.diplomatie.gouv.fr/ar/politiqueetrangere- de-la-France/etudier-enFrance/programmers-des-bourses-detude/article/bourse-Erasmus-mundus

15. Lashin, Muhammad. "Educational innovations in higher education in the European Union: Suggested mechanisms to benefit from them in the Arab region", The Twenty-first Annual Scientific Conference, Education and Modernization in the European Union Countries, The Egyptian Association for Comparative Education and Educational Administration, Cairo, 177-198, 2013

16. Ministry of Higher Education and Scientific Research, "Erasmus plus program" Retrieved on 10/3/2021 from https://www.mohe.pna.ps//InternationalUnits/tempus

17. Sata Ali, Baghdad. "The Tempus Program in Algeria 2002-2013," Ministry of Higher Education and Scientific Research, National Office Tempus, Algeria, pp.1-59, 2014

18. Scholarships and cooperation programs in higher education strengthen the EU's position as a center of excellence in education worldwide, Retrieved on 9/3/2021 from http://ec.europe.eu/education/programmes/mundus /index_en.htm .

19. Shtayyeh, Muhammad. "Development and Reform of Palestinian Higher Education: Problems and Future Effects", Ramallah, Palestinian Economic Council for Development and Reconstruction, PECDAR, Department of Economic Policies, 2009

\section{References}

1. Al Kathiri, Rashid. "Higher Education Programs in the Kingdom of Saudi Arabia: A Vision for Reform", Higher and Technical Education Foresight Symposium, King Saud University, Saudi Arabia, pp.166-178, 2005

2. Al-Amiri, Abdullah, "Requirements for the internationalization of higher education as an entrance to achieving global leadership for Saudi universities" a proposed conception, Ph.D. thesis, College of Education, Umm Al-Qura University, Saudi Arabia, 2013

3. Al-Jerjawi, Zaid. "Crises of Financing University Higher Education in Palestine", a paper presented to the Conference on the Status of Palestinian Universities, Arab American University, and Jenin 2005

4. Al-Kirani, Muhammad, "Proposals for the Internationalization of University Education in the Kingdom of Saudi Arabia for the Post-WTO Joining Phase", Fifth International Conference The Future of Arab Education Reform for a Knowledge Society, Experiences and Visions, Arab Center for Education and Development, King Saud University, p. 299, 2010

5. Al-Sayegh, Najat. "Partnership between schools and universities and the development of school administration in the Kingdom of Saudi Arabia", Journal of Educational Sciences, Volume 22, p. 4, Part 1.pp. p. 31-74, 2014

6. Badros, Wafa. Tempus as one of the European Union programs to support and develop higher education in Egypt, Supreme Council of Comparative Education Societies, and Egyptian Association for Comparative Education and Educational Administration, Vol. 17, p. 48, pp. 273-349, 2014

7. Editorial Board, International Monitor, "European Civil Society Program for Lifelong Learning: A Guide to Training, Education and DecisionMaking in the European Union", Ministry of Education-Deputy Agency for Planning and Information, Education Monitor, vol. 61, pp. 2722, 2016

8. Editorial Board, International Monitor, Global Trends in University Education for the Year 2015, Ministry of Education-Deputy Agency for Planning and Information, Education Observatory, p. 62, pp. 9-4, 2016.

9. Erasmus in Arabic, Retrieved on 12/3/2021 from http://erasmusbel3arabi.blogspot.com/2014/05/blo g-post_26.html 
20. Significance and Benefits of the ERASMUS Scholarship, Retrieved on 10/3/2021 from https://lookinmena.com/erasmus

21. The Islamic University of Gaza website, Retrieved on 12/3/2021 from web page, http://www.iugaza.edu.ps

22. The Islamic University, External Relations, Retrieved on 12/3/2021 from http://exrelation.iugaza.edu.ps/ar .

23. The Islamic University, Foreign Relations, International Cooperation, 2018, retrieved on 12/3/2021 from http://exrelation.iugaza.edu.ps/ar

24. The Norwegian Center for International Cooperation in Higher Education, International Monitor, "The Norwegian Cooperation Program: With European and Asian Countries in the Field of Higher Education", Ministry of Education Ministry Agency for Planning and Information, Education Observatory, p. 7, pp. 1-27, 2011. 